\title{
Perfect isolation of $\pi$-conjugated molecules on inorganic surfaces with [1]rotaxane structure for enhancing electrical properties
}

\section{Sheng-Ying Chou}

The University of Tokyo

Hiroshi Masai

University of Tokyo

Masaya Otani

The University of Tokyo

Gentaro Sakamoto

Osaka City Univeristy

Yusuke Yamada

Osaka City Univeristy

Yusuke Kinoshita

Ritsumeikan University

Hitoshi Tamiaki

Ritsumeikan University https://orcid.org/0000-0003-4797-0349

Takayoshi Katase

Hokkaido University

Hiromichi Ohta

Hokkaido University https://orcid.org/0000-0001-7013-0343

Tomoki Kondo

Kyoto University

Akinobu Nakada

Kyoto University https://orcid.org/0000-0001-6670-5044

Ryu Abe

Kyoto University

Takahisa Tanaka

University of Tokyo

Ken Uchida

University of Tokyo

Jun Terao ( $\nabla$ cterao@g.ecc.u-tokyo.ac.jp )

The University of Tokyo 
Article

Keywords: $\pi$-conjugated molecules, [1]rotaxane structure, inorganic surfaces

Posted Date: May 13th, 2021

DOI: https://doi.org/10.21203/rs.3.rs-464533/v1

License: (c) (i) This work is licensed under a Creative Commons Attribution 4.0 International License. Read Full License 


\section{Perfect isolation of $\pi$-conjugated molecules on inorganic surfaces}

with [1]rotaxane structure for enhancing electrical properties

3 Sheng-Ying Chou, ${ }^{1}$ Hiroshi Masai, ${ }^{1}$ Masaya Otani, ${ }^{1}$ Gentaro Sakamoto, ${ }^{2}$ 4 Yusuke Yamada, ${ }^{2}$ Yusuke Kinoshita, ${ }^{3}$ Hitoshi Tamiaki, ${ }^{3}$ Takayoshi Katase, ${ }^{4,7}$ 5 Hiromichi Ohta, ${ }^{4}$ Tomoki Kondo, ${ }^{5}$ Akinobu Nakada, ${ }^{5,8}$ Ryu Abe, ${ }^{5}$ Takahisa 6 Tanaka, ${ }^{6}{ }^{\text {Ken Uchida, }}{ }^{6}$ Jun Terao ${ }^{1 *}$

7 Affiliations

$8{ }^{1}$ Department of Basic Science, Graduate School of Arts and Sciences, The University of Tokyo,

9 Meguro-ku, Tokyo, Japan

Sheng-Ying Chou, Hiroshi Masai (orcid.org/0000-0002-4231-1320), Masaya Otani \& Jun Terao

11 (orcid.org/0000-0003-1867-791X)

$12{ }^{2}$ Department of Applied Chemistry and Bioengineering, Graduate School of Engineering, Osaka

13 City University, Sumiyoshi-ku, Osaka, Japan

14 Gentaro Sakamoto \& Yusuke Yamada (orcid.org/0000-0003-0088-0549)

$15{ }^{3}$ Department of Applied Chemistry, Graduate School of Life Sciences, Ritsumeikan University,

16 Kusatsu-shi, Shiga, Japan

17 Yusuke Kinoshita (orcid.org/0000-0001-7681-2644) \& Hitoshi Tamiaki (orcid.org/0000-0003-4797-

18 0349)

$19{ }^{4}$ Research Institute for Electronic Science, Hokkaido University, Kita-ku, Sapporo, Japan

20 Takayoshi Katase (orcid.org/0000-0002-2593-7487) \& Hiromichi Ohta (orcid.org/0000-0001-7013-0343)

$21{ }^{5}$ Department of Energy and Hydrocarbon Chemistry, Graduate School of Engineering, Kyoto

22 University, Nishikyo-ku, Kyoto, Japan

23 Tomoki Kondo, Akinobu Nakada (orcid.org/0000-0001-6670-5044) \& Ryu Abe (orcid.org/0000-0001-

24 8592-076X)

$25{ }^{6}$ Department of Materials Engineering, The University of Tokyo, Bunkyo-ku, Tokyo, Japan 
Takahisa Tanaka \& Ken Uchida (orcid.org/0000-0001-8307-5232)

$27{ }^{7}$ Laboratory for Materials and Structures, Institute of Innovative Research, Tokyo Institute of

28 Technology, Midori-ku, Yokohama, Japan

29 Takayoshi Katase

$30 \quad{ }^{8}$ Department of Applied Chemistry, Faculty of Science and Engineering, Chuo University, Tokyo,

31 Japan; Precursory Research for Embryonic Science and Technology (PRESTO), Japan Science and

32 Technology Agency (JST), Kawaguchi, Saitama, Japan

33 Akinobu Nakada

34

35

Contributions

36

H.M. and J.T. designed and directed the project. S.-Y. C. performed the synthetic experiments and collected

37 the central data. O.M. collaborated with S.-Y. C. to investigate the interfacial charge transfer. G.S. and Y.Y. performed and interpreted the electrocatalysis. Y.K. and H.T. synthesized the Co-catalyst. T.Ka. and H.O. manufactured the single-crystalline ITO substrates. T.Ko., A.K. and R.A. investigated the optical analyses of the modified ITO substrates. T.T. and K.U. performed and analyzed XPS. S.-Y. C. and H.M. wrote the

41 manuscript. All authors have approved the manuscript.

\section{Corresponding author}

43 Correspondence to: Jun Terao

44 orcid.org/0000-0003-1867-791X

45 Email: cterao@g.ecc.u-tokyo.ac.jp

\section{Abstract}

$47 \pi$-Conjugated molecules have been utilized to functionalize inorganic surfaces to form organic-inorganic

48 hybrid materials. However, the intrinsically strong $\pi-\pi$ interaction results in undesirable aggregations on 49 the inorganic surface, thereby disturbing the charge transfer through the organic-inorganic interface. In this 
study, a new strategy was developed using insulated $\pi$-conjugated molecules bearing a [1]rotaxane structure,

51 where the $\pi$-conjugation was covered with covalently linked permethylated $\alpha$-cyclodextrins. Aggregation-

52 free immobilization was achieved on an inorganic surface by using insulated molecules to suppress

53 intermolecular interaction. In the presence of these insulated molecules, the hybrid interface displayed

54 excellent interfacial electrical properties. Moreover, the functionalized hybrid surface was utilized as an

55 electrocatalyst to produce hydrogen peroxide using a Co(II)-chlorin complex, wherein the catalytic

56 efficiency was improved dramatically by utilizing insulated molecules as bridging moieties at the interface.

57 These results demonstrate that the insulation of $\pi$-conjugated molecules is a powerful strategy for modifying

58 inorganic surfaces.

59

60

61

62

63

64

65

66

67 have been achieved via self-assembled monolayers (SAMs), ${ }^{8}$ covalent bond formations, ${ }^{9,10}$ and

68 depositions. ${ }^{11,12}$ However, these classical methods are only suitable for simple and limited conjugated

69 molecules (i.e., unexpanded $\pi$-conjugation) to provide uniform and ordered hybrid interfaces. Although $\pi$ -

70 expanded conjugated molecules offer high functionalities for such electrical devices, they readily form

71 objectionable aggregation on surfaces, owing to their strong $\pi-\pi$ interaction (Fig. 1a). ${ }^{13-15}$ This aggregation

72 induces disordering and large protrusions on the surface; therefore, rather than direct injection into the

73 inorganic materials, unanticipated charge transfer between the adjacent molecules occurs on the surface of

74 these materials. This decreases the charge-transfer efficiency of the material. Thus, $\pi$-expanded conjugated 
molecules for electrical devices result in undesirable aggregation, limiting the improvement of the functional device performance. Paving the optimum conductive pathways at the interface by inhibiting $\pi$ aggregation is therefore critical to improve the material performance, especially for electrical devices with

a

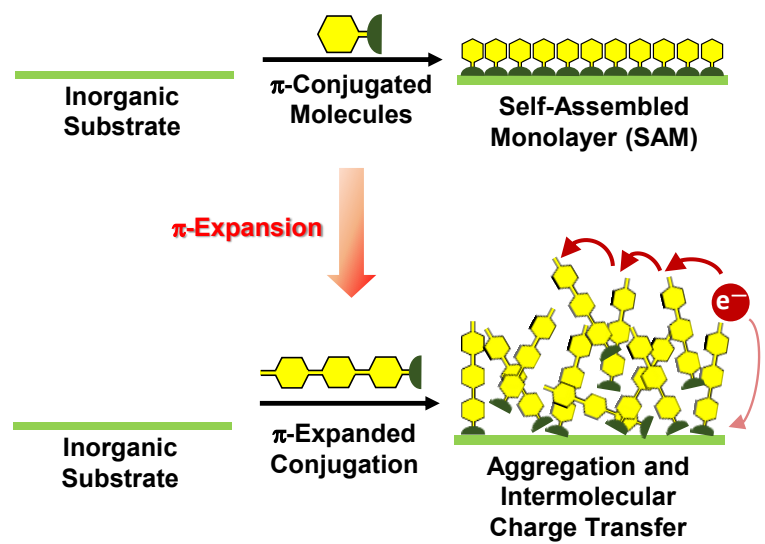

b
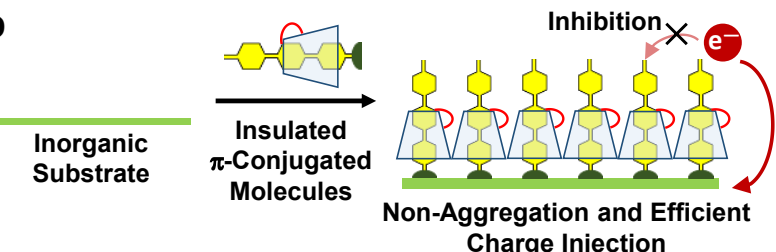

C

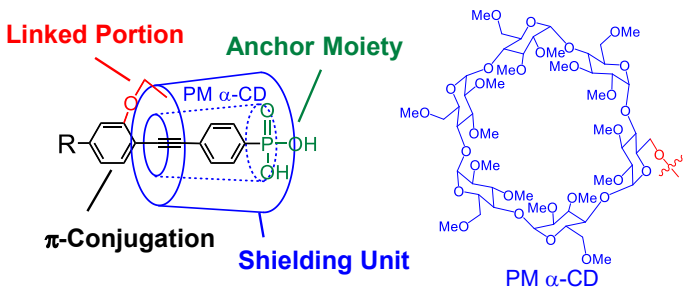

92 Fig. 1 Conceptual illustration of modification of inorganic surface using $\pi$-conjugated molecules. a

93 SAMs constructed by unexpanded $\pi$-conjugated molecules (top) and intermolecular charge transfer caused 
94 by undesirable aggregation due to strong aromatic interaction derived from the expansion of the $\pi$ 95 conjugated backbone (bottom). b Non-aggregation and efficient charge injection because of $\pi-\pi$ interaction 96 and intermolecular charge-transfer inhibition using [1]rotaxane structure. c Molecular design of the 97 conjugated molecules bearing the [1]rotaxane structure for surface immobilization.

98

Recently, rotaxane structures have gained importance as a promising method to inhibit $\pi-\pi$ interaction..$^{21,22}$ The cyclic molecules efficiently cover the $\pi$-conjugated axles and inhibit unfavorable $\pi$ aggregation. ${ }^{23,24}$ In particular, pseudorotaxanes, in which cyclic and axis molecules dynamically form threading structures, ${ }^{25,26}$ have been utilized for hybrid modification because of their facile in situ preparation. ${ }^{27}$ However, owing to their lack of stoppers, pseudorotaxanes can dynamically dissociate to form irregular structures on the hybrid interfaces, including aggregated $\pi$-conjugated molecules and empty cyclic molecules. These unclear and aggregated structures decrease the electrical properties of the hybrid interface. Consequently, examples of hybrid materials utilizing pseudorotaxanes to improve the electrical performance in terms of effective electron injections at the hybrid interface have rarely been reported. ${ }^{28-31}$ Therefore, a new strategy for highly advanced molecular designing of $\pi$-expanded conjugated molecules, to attain fine interface immobilization, would create new platforms toward further growth in this field of nanoscience.

To address these concerns, we introduced the [1]rotaxane strategy (Figs. 1b and 1c). ${ }^{32-36}$ In contrast to common rotaxane structures, [1]rotaxane structures prevent macrocycles from dissociating, without any bulky stopper units in the rotaxanes. The defect-free insulation improves their conversion ratio on the axles and ensures that the conjugated molecules are highly insulated. As a result, the physical properties derived from their conjugation are preserved from the effect of their $\pi-\pi$ interaction, even in the solid state, because of the high proportion of covering structures. ${ }^{37-41}$ Their advantage as highly protected structures inspired the design of a novel insulated conjugated molecule for immobilization on inorganic surfaces. The defectfree structures contribute non-aggregation structures with high density and uniform $\pi$-expanded conjugation immobilization at the hybrid interface to inhibit intermolecular charge transfer. Moreover, the finely 
controlled interface at the molecular scale provides high-performance electrical devices via efficient charge

121 transfer through each $\pi$-conjugated backbone. In this study, we synthesized an insulated conjugated

122 molecule to achieve independent immobilization on inorganic substrates. The molecule comprises

123 phenylene-ethynylene (PE)-based $\pi$-conjugation covered by a linked permethylated $\alpha$-cyclodextrin (PM $\alpha-$

$124 \mathrm{CD}$ ) as the shielding unit, and displays high solubility in organic solvents together with a deep cavity (Fig.

125 1c). As an anchoring moiety to the substrates, phosphonic acid was directly introduced at the end of the

126 conjugated section to allow strong interaction and to transfer the charge to various metal oxide substrates s.42 $^{9,4}$

127 such as indium tin oxide (ITO) and fluorine-doped tin oxide (FTO), which are utilized as electrodes in 128 electrical devices. The insulation effects were investigated to clarify the high-degree independency and 129 excellent electrical properties on the hybrid interface compared to those on the uninsulated counterparts, 130 owing to the inhibition of intermolecular interactions by three-dimensional encapsulation. In addition, the 131 hybrid system based on [1]rotaxanes was applied to electrocatalysis, revealing marked improvement in the 132 catalytic efficiency. The results demonstrated that enhanced charge-transfer and catalytic efficiencies were 133 achieved because the [1]rotaxane strategy efficiently isolated the $\pi$-conjugated molecules to inhibit $\pi-\pi$ 134 interaction. This strategy shows great potential for application to various electric devices.

\section{Results}

\section{Synthesis of Insulated Junction Molecules}

The immobilization behavior of cyclic-insulated molecules was investigated using insulated conjugated molecule 3. Precursor 1 bearing PM $\alpha-\mathrm{CD}$ and terminal ethyl-protected phosphonic acid was prepared according to previously reported procedures. ${ }^{43}$ Moreover, 1 was converted into the corresponding

141 insulated structure 2 quantitatively by hydrophobic-hydrophilic interactions in a heated $\left(60{ }^{\circ} \mathrm{C}\right)$ high142 polarity solvent $\left(\mathrm{MeOH} / \mathrm{H}_{2} \mathrm{O}=1: 1\right)$. This was followed by deprotection of the ethyl ether groups in $\mathbf{1}$ and 1432 using trimethylsilyl bromide (TMSBr) and triethylamine (TEA) in dichloromethane $\left(\mathrm{CH}_{2} \mathrm{Cl}_{2}\right)$ to obtain 
144 the uninsulated and insulated phosphonic acid-derived molecules 3' and 3, respectively, (Fig. 2a). The high 145 activation barrier for the threading/dethreading transformations ${ }^{44}$ was confirmed in previous works ${ }^{45-48}$ and 146 hence, heating the solvent mixture was essential for converting 1 to $\mathbf{2}$ and vice versa. Thus, these structures 147 displayed kinetic stability at ambient temperature. The high kinetic stability at room temperature allowed 148 the selective preparation of $\mathbf{3}^{\prime}$ and $\mathbf{3}$ via deprotection of the ethyl ether groups in $\mathbf{1}$ and $\mathbf{2}$, respectively. In 149 the ${ }^{1} \mathrm{H}$ NMR spectra (Fig. 2b), the chemical shifts in the aromatic region of $\mathbf{3}$ were clearly shifted downfield 150 relative to those of the uninsulated counterpart $3^{\prime}$, owing to deshielding by the threading structure. ${ }^{46}$ The 151 loss of ethyl proton signals in the aliphatic region confirmed successful deprotection without any unwanted 152 changes to the insulated/uninsulated structures. In addition, insulated molecule $\mathbf{3}$ was kinetically stable even 153 in low-polarity solvents, in which the uninsulated structures are thermodynamically favored. Indeed, the insulation remained intact after storage in $\mathrm{CHCl}_{3}$ at room temperature for one day.

\section{Insulation Effects on the Surface Morphology}

The insulation effects on the molecular morphologies of $\mathbf{3}$ ' and $\mathbf{3}$ after their immobilization on the metal oxide surface were next investigated. To establish whether the surface protrusions were created by the immobilized species or the surface substrate itself, commercially unavailable single-crystalline ITO substrates with ultra-flat surfaces (root mean square roughness, $<0.2 \mathrm{~nm}$ ), fabricated by pulsed laser deposition on single crystal YSZ plate, were utilized. ${ }^{49,50}$ Compared to those of amorphous ITO, the individual heights of $\mathbf{3}^{\prime}$ and $\mathbf{3}$ on the single-crystalline ITO surfaces were easily and correctly analyzed in detail using atomic force microscopy (AFM). The crystalline ITO substrates were modified by dipping into a low-concentration $(50 \mu \mathrm{M}) \mathrm{MeOH}$ solution of $\mathbf{3}^{\prime}$ or $\mathbf{3}$. The low concentration prevented high-density adsorption of the conjugated molecules on the ITO surface, thereby enabling the analysis of the individual height of each adsorption species by AFM. Consequently, the AFM image revealed that the singlecrystalline ITO substrate, which showed a regular step-and-terrace structure, similar to that reported by Ohta et al., ${ }^{49,50}$ was modified by the numerous protrusions of insulated conjugated molecule 3 (Fig. $2 \mathrm{c}$ ). The height distribution of this molecule on the single-crystalline ITO surface mostly ranged from 0.9 to $1.9 \mathrm{~nm}^{51}$ 
(Fig. 2e), which approached the calculated length of $\mathbf{3}$ (1.7 nm; Fig. S2). This indicated that the observed structure was the attached single molecule. The formation of huge protrusions, owing to undesirable

171 aggregation of the uninsulated conjugated molecule $3^{\prime}$ on the single-crystalline ITO surface, was observed 172 (Figs. 2d and 2f). In the histogram of immobilized 3' (Fig. 2f, inset), the height frequency exceeded $2 \mathrm{~nm}$,

173 which was considered as aggregation, in more than $10 \%$ of the graph. This indicated that for uninsulated

174 3', surface aggregation occurred even when a low-concentration solution was utilized for surface

175 modification. Indeed, although uninsulated $3^{\prime}$ possessed PM $\alpha-\mathrm{CD}$ as a bulky side chain, the strong

176 intermolecular interactions between the expanded conjugation resulted in an unfavorable aggregated

177 structure on the ITO substrate.
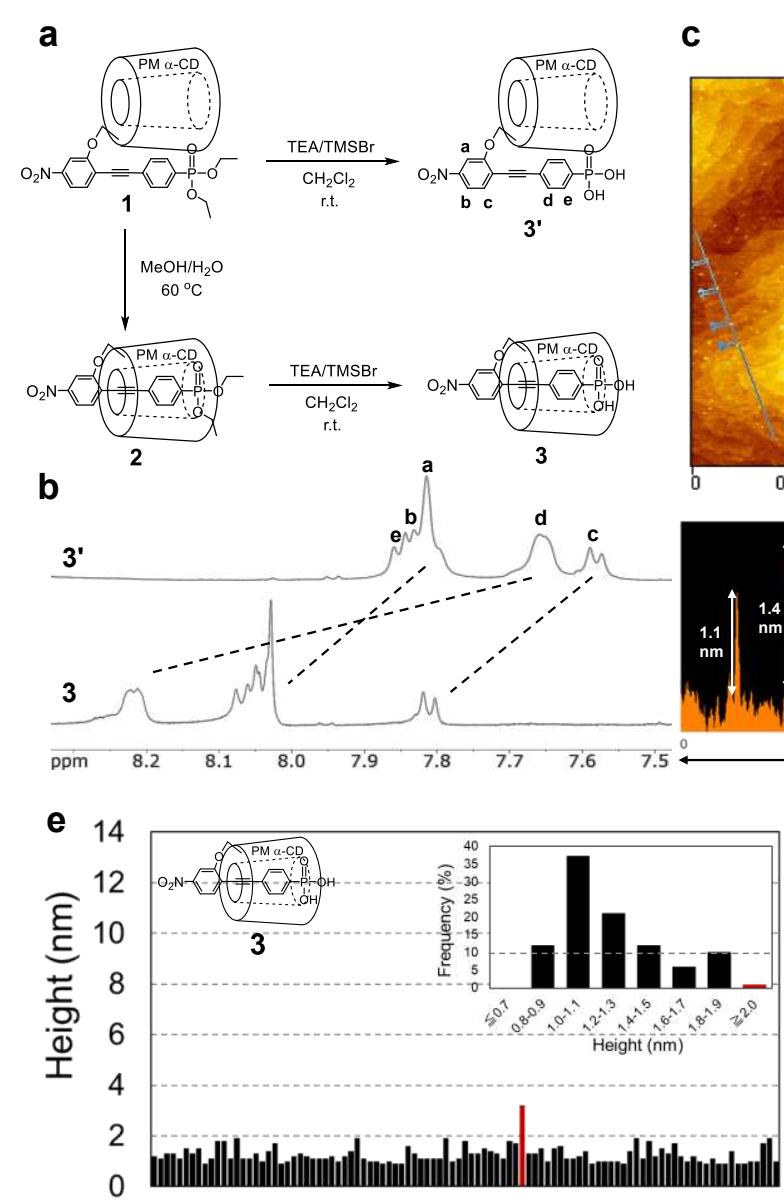

C
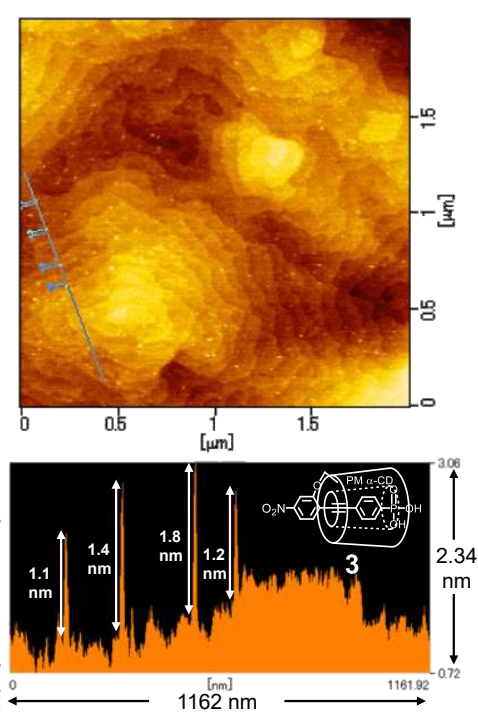

f 14

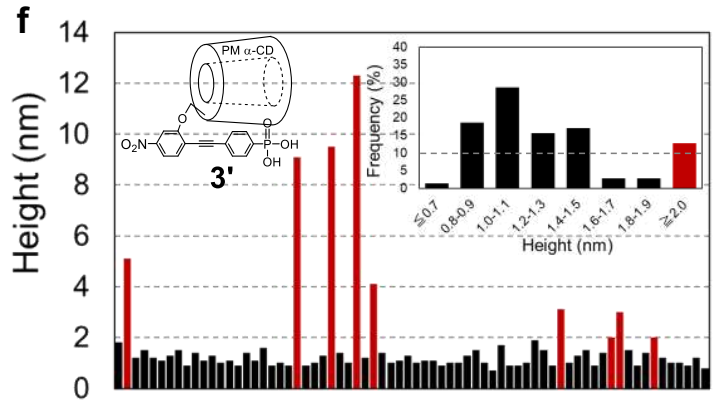


181 NMR spectra of (top) 3' and (bottom) 3. AFM images of the single-crystalline ITO substrates modified by 182 c 3 and $\mathbf{d} \mathbf{3}^{\prime}$ with the plan views and cross-sectional profiles. Height of each protrusion of e immobilized $\mathbf{3}$ 183 (99 counts; inset: histogram of height analyses) and f immobilized 3' (70 counts; inset: histogram of height 184 analyses) in the AFM image.

\section{Insulation Effects on the Interface Electronic Properties}

To analyze the electrical properties of the immobilized molecules, $\mathbf{4}$ and $\mathbf{4}^{\prime}$ 'bearing redox-active

187 ferrocene units were next prepared (Scheme S3). The surface coverage concentration $(\Gamma)$ and other electrical

188 properties were then determined using cyclic voltammetry. The experiment for calculating the $\Gamma$ values was

189 carried out in a $0.1 \mathrm{M}$ solution of tetrabutylammonium hexafluorophosphate $\left(\mathrm{TBAPF}_{6}\right)$ in $\mathrm{CH}_{2} \mathrm{Cl}_{2}$. $\Gamma$ values

190 were then obtained from the cyclic voltammograms using the formula: ${ }^{52}$

$$
\Gamma=Q / n F A
$$

where $Q$ is the charge obtained by integrating the anodic peak in the cyclic voltammogram (gray area in Fig. 3a), $n$ is the number of electrons transferred during the redox process ( $n=1$ for $\mathbf{4}$ and $\mathbf{4}^{\prime}$ ), $F$ is the Faraday constant $\left(F=9.65 \times 10^{4} \mathrm{~s} \mathrm{~A} \mathrm{~mol}^{-1}\right)$, and $\mathrm{A}$ is the immersed area of the electrode. The maximum $\Gamma$ value of 4 was observed when the ITO substrate was immersed into a $1000 \mu \mathrm{M}$ MeOH solution of 4 (Table S2). Subsequently, the ITO substrate was also immersed into a $1000 \mu \mathrm{M} \mathrm{MeOH}$ solution of $\mathbf{4}^{\prime}$. The $\Gamma$ values

197 of insulated 4 and uninsulated $\mathbf{4}^{\prime}$ are summarized in Table S3. The $\Gamma$ value of $\mathbf{4}^{\prime}$ was approximately twice 198 that of 4 because of the immense protrusions observed on the AFM images, which were created by 199 aggregation of uninsulated 4' on ITO (Fig. 3c). The cyclic voltammograms of the 4-modified ITO electrode 200 were next recorded at different scan rates. The plot of peak current versus scan rate (Figs. 3b and S3a) 201 revealed a linear relationship, confirming that 4 was adsorbed on the electrode surface. The peak current 202 corresponded to the current from the electrode-adsorbed redox species according to the formula: ${ }^{53,54}$

$$
i_{p}=\frac{n^{2} F^{2}}{4 R T} v A \Gamma
$$


204 where $i_{p}$ is the peak current and $v$ is the scan rate. In addition,there was negligible change in the $\Gamma$ value of 205 immobilized 4 when the potential sweep was repeated 25 times (Figs. S4a and S4b). This indicated that the 206 modified surface prepared utilizing the insulated molecule 4 displayed significant redox durability.

207 In the cyclic voltammograms, the separation between the anodic and cathodic peaks of the redox208 active species immobilized on the electrode surface is designated as $0 \mathrm{mV}$ under ideal reversible 209 conditions. ${ }^{55}$ At a scan rate of $100 \mathrm{mV} \mathrm{s}^{-1}$, the peak-to-peak separation was $3 \mathrm{mV}$ for both immobilized 4 210 (Fig. 3a) and immobilized 4' (Fig. S3b). This value is small enough to be in excellent agreement with the 211 ideal value for the reversible response of a surface-adsorbed species. Moreover, the value of the full width 212 at half maximum (FWHM) in the cyclic voltammograms was utilized to assess the immobilized molecules 213 at the point of the electrostatic interaction with the neighboring species, ${ }^{53}$ i.e., as the repulsion forces were 214 dominant, the redox peak was wider than the ideal width $\left(90.6 / n \mathrm{mV}\right.$ at $25^{\circ} \mathrm{C}, n=1$ for $\mathbf{4}$ and $\left.\mathbf{4}^{\prime}\right)$, while 215 when the attraction forces were dominant, the redox peak became narrower than the ideal width. ${ }^{56}$ Moreover, 216 while the FWHM value of immobilized $4^{\prime}(77 \mathrm{mV})$ was smaller than the ideal value (Fig. S3b), that of 217 immobilized $4(88 \mathrm{mV})$ approached the ideal value (Fig. 3a). The smaller FWHM of $\mathbf{4}^{\prime}$ on the ITO surface 218 was attributed to the electrostatic interaction between neighboring molecules due to unwanted aggregation. 219 On the other hand, the intermolecular interaction between the molecules of 4 on the ITO surface was 220 efficiently inhibited by the [1]rotaxane structure, providing isolated $\pi$-conjugated cores even at the organic221 inorganic interface. 
a

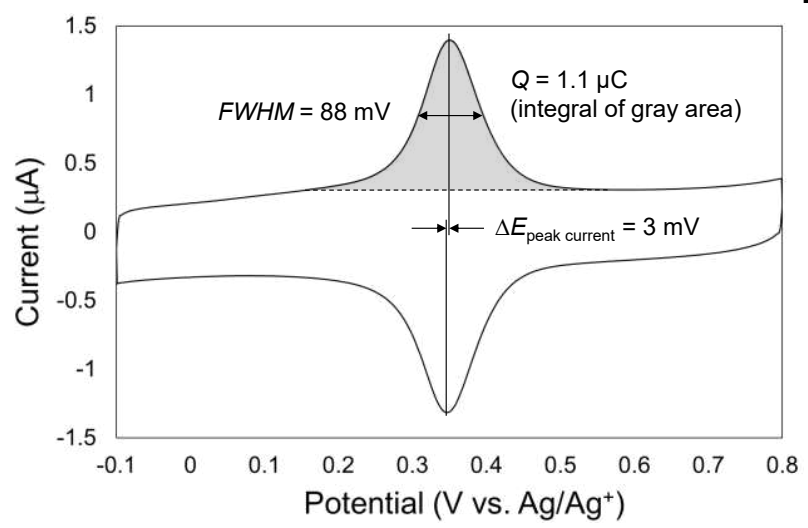

b

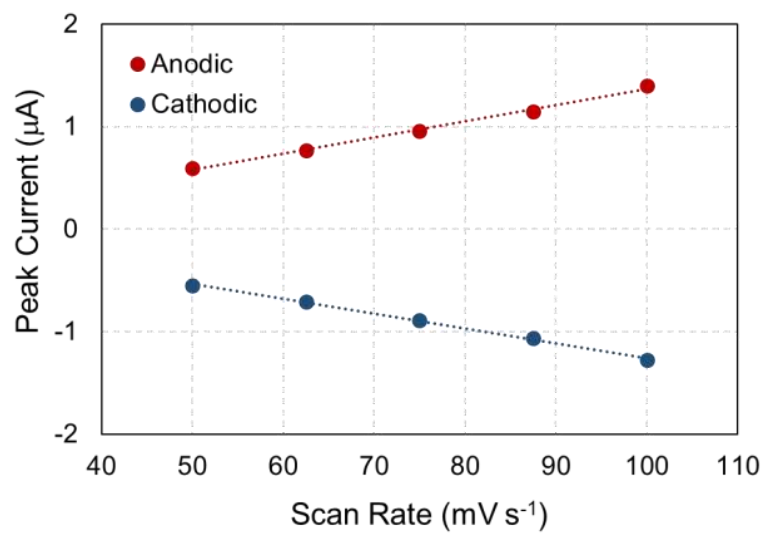

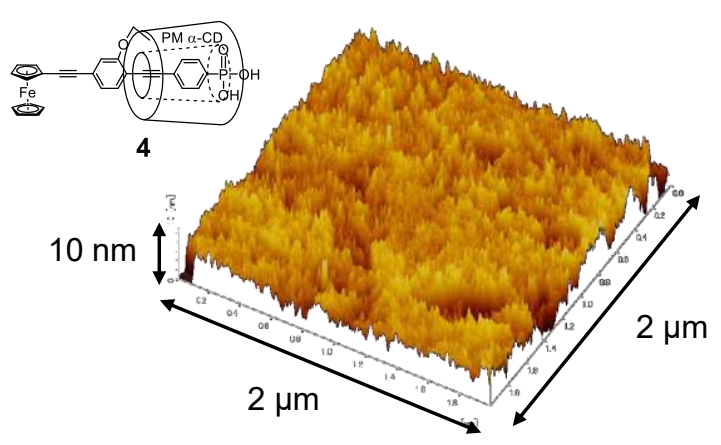

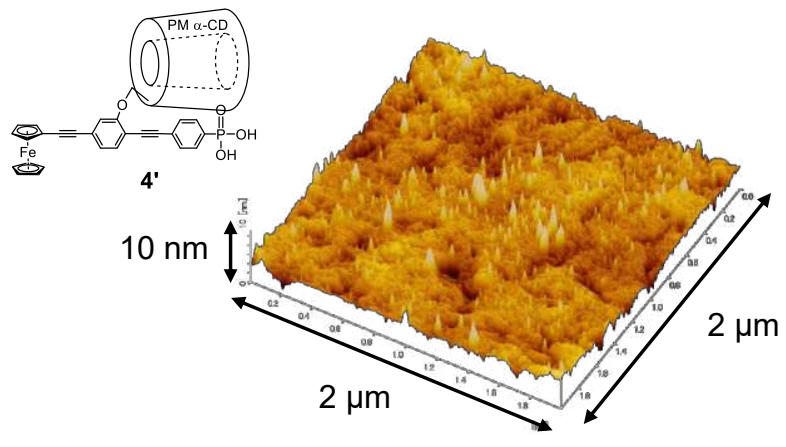

Fig. 3 Interfacial electronic properties and morphology of modified ITO substrates. a Cyclic voltammogram of immobilized 4 at a scan rate of $100 \mathrm{mV} \mathrm{s}^{-1}$. Conditions: $100 \mathrm{mM} \mathrm{CH}_{2} \mathrm{Cl}_{2}$ solution of TBAPF $_{6}$. b Plot of anodic and cathodic peak currents of immobilized 4 versus the scan rates. $\mathbf{c}$ AFM images of the ITO substrate modified with (left) 4 and (right) $4^{\prime}$.

The increase in peak-to-peak separation with faster scan rates was attributed to the slow charge transfer between the ITO and immobilized redox-active species. ${ }^{57,58}$ To investigate the insulation effects on the charge transfer between the ferrocene unit and ITO electrode, the variation in the peak-to-peak separation potentials (Fig. $4 \mathrm{a} ; \Delta E=E_{p}-E^{\circ}$ ', where $E_{p}$ is the peak potential and $E^{\circ}$ is the formal potential) with increasing scan rate was determined to construct the trumpet plots (Fig. 4b) ${ }^{57,59,60}$ While the peak-to-peak separation of uninsulated $4^{\prime}$ occurred at $\log (v)=0.6\left(v=4 \mathrm{~V} \mathrm{~s}^{-1}\right)$, insulated 4 did not display any significant peak-to-peak separation, even at a high scan rate of $\log (v)=2\left(v=100 \mathrm{~V} \mathrm{~s}^{-1}\right)$. This indicated that the rate of charge transfer between the ITO electrode and $\mathbf{4}$ increased, owing to the insulated structure. 
In our previous study on the single molecular conductance of insulated molecules, the conductance of single

237 insulated conjugation was lower than that of the corresponding uninsulated molecule. This occurred

238 because the $\pi$-conjugated backbone was twisted, owing to insulation by $\mathrm{PM} \alpha-\mathrm{CD} .{ }^{61} \mathrm{In}$ this study, however,

239 the insulated structure improved the charge-transfer efficiency relative to the uninsulated counterpart,

240 indicating that the insulation enhanced the charge transfer at the interface rather than on the $\pi$-conjugated

241 core. The highly efficient charge transfer between $\mathbf{4}$ and the ITO electrode were attributed to the inhibition

242 of $\pi-\pi$ interaction and intermolecular charge transfer. Indeed, the intermolecular charge transfer between

243 the bare $\pi$-conjugated cores of uninsulated $4^{\prime}$ decreased the charge-transfer efficiency. Thus, appropriate $\pi$ -

244 aggregation inhibition at the organic-inorganic interface utilizing [1]rotaxanes structures is a promising

245 strategy for developing exceptional electrical devices, owing to the high charge-transfer efficiency. a shift of anodic peak potential

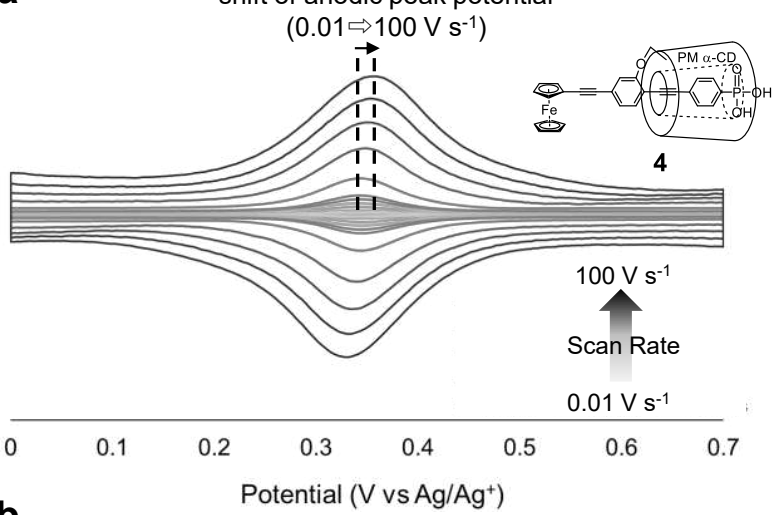

b

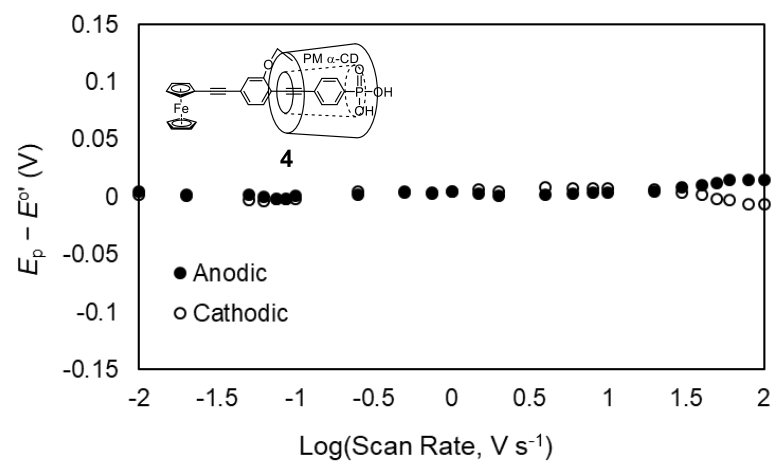

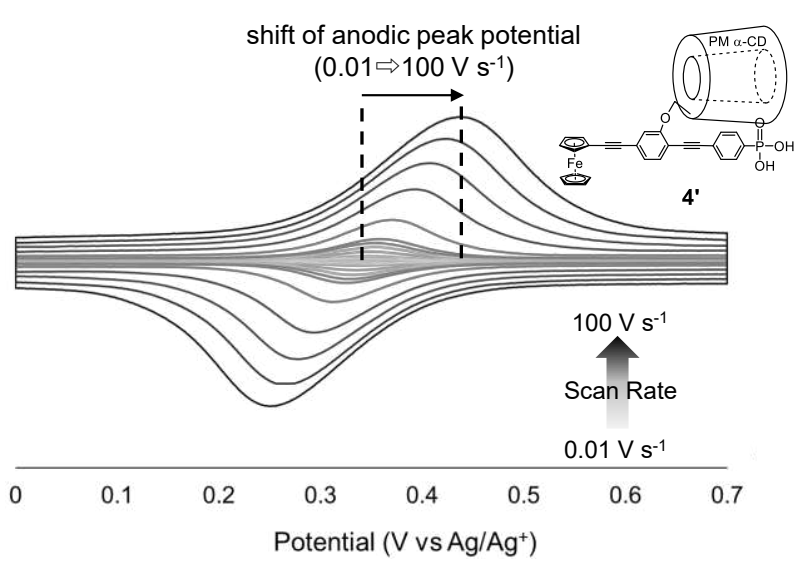

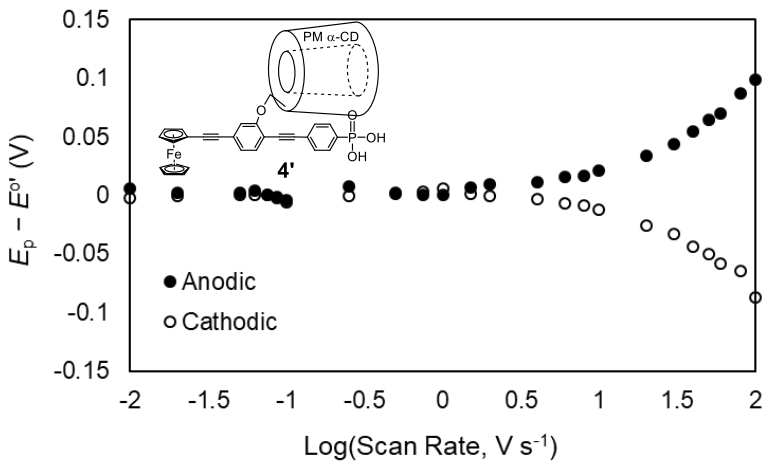

247 Fig. 4 Interfacial charge transfer. a Cyclic voltammograms of immobilized 4 and $\mathbf{4}^{\prime}$ at various scan rates.

248 b Trumpet plot for immobilized 4 and $\mathbf{4}^{\prime}$. Conditions: $0.1 \mathrm{M} \mathrm{CH}_{2} \mathrm{Cl}_{2}$ solution of TBAPF 6 . 


\section{Surface Functionalization with Metalloporphyrin}

The isolated surface $\pi$-conjugations were effectively applied to electrical devices based on organicinorganic hybrid materials. To provide functionalities on the hybrid materials, we focused on the immobilization of metal complexes through metal-ligand coordination, which have been widely utilized for dyes and surface inorganic catalysis. ${ }^{62,6362}$ In particular, the modification of metalloporphyrin analogs onto metal oxide surfaces have been effectively applied to artificial photosynthesis and electrosynthesis devices. ${ }^{64,65}$ In the current study, the 4-pyridyl group was introduced as a coordination point into insulated and uninsulated structures to obtain $\mathbf{5}$ and $\mathbf{5}^{\prime}$, respectively (Scheme S4). To evaluate the potential of $\mathbf{5}$ for application to surface engineering, we first investigated the complexation behavior between $\mathbf{5}$ (or $\mathbf{5}^{\prime}$ ) and $\mathbf{R h}^{\text {IIII }} \mathbf{C l ( O E P )}$ (OEP: octaethylporphyrin), both in the solution system and on the surface system. In the former, the coordination between compound $\mathrm{S} 12^{66}$ and $\mathbf{R h}{ }^{\mathrm{III}} \mathbf{C l}(\mathbf{O E P})$ was confirmed from the characteristic up-field shifts observed for complexation in the ${ }^{1} \mathrm{H}$ NMR spectra (Figs. S5 and S6). In addition, the complexation was applied to the surface modifications. Thus, the ITO substrate was immersed in a solution of $\mathbf{5}$ or $\mathbf{5}^{\prime}$ in $\mathrm{MeOH}(1000 \mu \mathrm{M})$ overnight, and subsequently submerged in a solution of $\mathbf{R h}{ }^{\mathrm{III}} \mathbf{C l}(\mathbf{O E P})$ in $\mathrm{CH}_{2} \mathrm{Cl}_{2}(200 \mu \mathrm{M})$ for $2 \mathrm{~h}$ to obtain $\mathbf{R h}{ }^{\mathrm{III}} \mathbf{C l}(\mathbf{O E P})-\mathbf{5} / \mathrm{ITO}$ (Fig. 5a) or $\mathbf{R h}{ }^{\mathrm{III}} \mathbf{C l}(\mathbf{O E P})-$ 5'/ITO, respectively. In the AFM images of the modified substrates (Fig. S7), there were no distinct aggregation structures on the surface of $\mathbf{R h}{ }^{\text {III }} \mathbf{C l}(\mathbf{O E P})-5 /$ ITO. In contrast, many large protrusions were observed as aggregation structures on its uninsulated counterpart. Surface modification of the Rh-porphyrin complex was confirmed by UV-vis absorption and XPS analysis. In the differential UV-vis absorbance spectrum of $\mathbf{R h}{ }^{\mathrm{III}} \mathbf{C l}(\mathbf{O E P})-5 / \mathrm{ITO}$ (Fig. S8b, red line), the characteristic Soret and Q bands of porphyrin were observed. Conversely, no characteristic porphyrin absorption bands were observed following the direct immersion of the ITO substrate into the $\mathbf{R h}{ }^{\text {IIII }} \mathbf{C l}(\mathbf{O E P})$ solution without immersion into a solution of 5 (Fig. S8b, blue line). Moreover, the maximum absorption wavelength of $\mathbf{R h}^{\text {III }} \mathbf{C l}(\mathbf{O E P})-\mathbf{5} /$ ITO corresponded to that observed in the $\mathbf{R h}{ }^{\mathrm{III}} \mathbf{C l}(\mathbf{O E P})-\mathbf{S 1 2}$ solution (Fig. 5b). The XPS survey spectra of

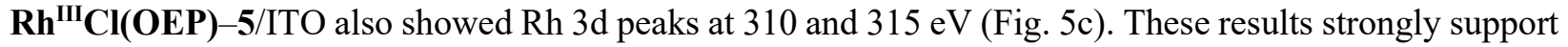


the formation of $\mathbf{R h}{ }^{\mathrm{III}} \mathbf{C l}(\mathbf{O E P})-\mathbf{5}$ complexes with ITO as the hybrid interface. According to the integral areas of the $R h 3 d_{3 / 2}$ and $P 2 p$ peaks, which were normalized by that of the In $3 \mathrm{~d}$ peak derived from the ITO

277 substrate, the ratio of Rh-porphyrin-to-insulated $\mathbf{5}$ in $\mathbf{R h}{ }^{\mathrm{III}} \mathbf{C l}(\mathbf{O E P})-\mathbf{5} / \mathrm{ITO}$ was 1:1 (Table S4). On the other

278 hand, that between Rh-porphyrin and $\mathbf{5}^{\prime}$ in $\mathbf{R h}^{\mathrm{III}} \mathbf{C l}(\mathbf{O E P})-\mathbf{5}^{\prime} / \mathrm{ITO}$ was $1.7: 1$, because of the non-

279 independence of the uninsulated molecule on the surface. According to the space filling model obtained by calculation (Fig. S10), the molecular size of $\mathbf{R h}{ }^{\text {III }} \mathbf{C l}(\mathbf{O E P})$ was near-identical to the diameter of PM $\alpha-\mathrm{CD}$.

281 This permitted high-density packing of the metalloporphyrin portion, while simultaneously avoiding metalloporphyrin overlapping on the metal oxide surface. Thus, this sequentially coordinated modification utilizing insulated $\mathbf{5}$ allowed an easy approach for introducing a large metalloporphyrin of high crystallinity and low solubility onto the metal oxide surface via metal-ligand axial coordination. This was achieved the metal oxide surface.

a

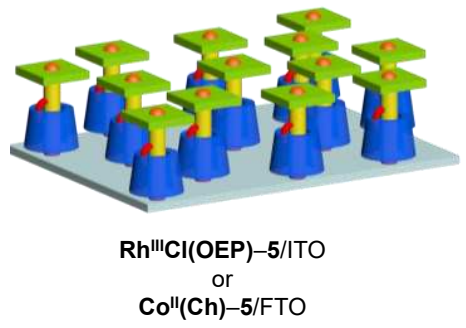

b

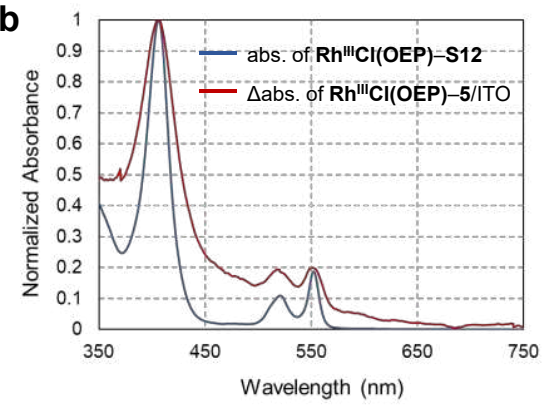

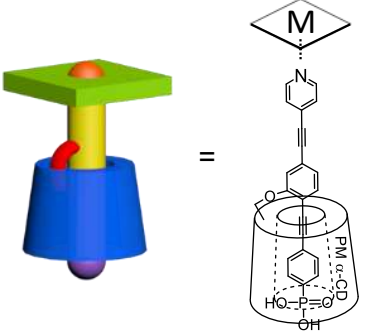

C

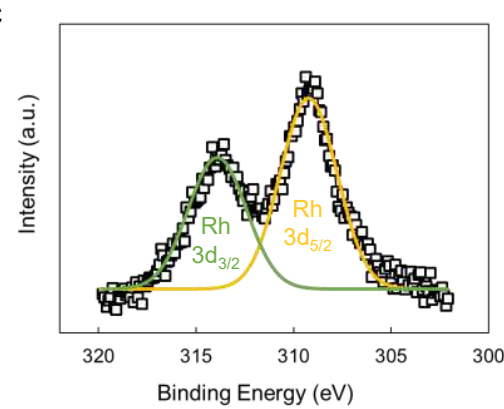

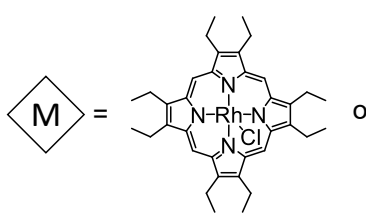

$\mathrm{Rh}^{\mathrm{III}} \mathrm{Cl}(\mathrm{OEP})$

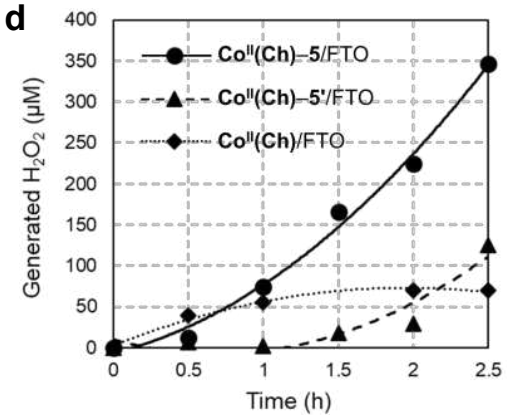

Fig. 5 Coordination of metalloporphyrin and its analog to insulated molecules. a Image of $\mathbf{R h}^{\text {III }} \mathbf{C l}(\mathrm{OEP})-5 /$ ITO and $\mathbf{C o}^{\mathrm{II}}(\mathrm{Ch})-5 /$ FTO. b Normalized UV-vis absorption spectra of the 
of $\mathrm{Rh} 3 \mathrm{~d}_{3 / 2}$ (green line) and $\mathrm{Rh} 3 \mathrm{~d}_{5 / 2}$ (yellow line) for $\mathbf{R h}{ }^{\mathrm{III}} \mathbf{C l}(\mathbf{O E P})-\mathbf{5} / \mathrm{ITO}$ substrate. $\mathbf{d ~} \mathrm{H}_{2} \mathrm{O}_{2}$ production of $\mathbf{C o}^{\text {II }}(\mathbf{C h})-5 /$ FTO (solid line), Co ${ }^{\text {II }}(\mathbf{C h})-5^{\prime} /$ FTO (dashed line), and Co' $\mathbf{C o}^{\text {II }}(\mathbf{C h}) /$ FTO (dotted line) as working electrodes. The reactions were carried out by applying constant voltage $(E=0.41 \mathrm{~V}$ vs. $\mathrm{Ag} / \mathrm{AgCl})$ 294 in an $\mathrm{O}_{2}$-saturated perchlorate buffer solution ( $\mathrm{pH} \mathrm{1.3,100} \mathrm{mM,11} \mathrm{mL).}$

295

\section{Electrocatalysis for $\mathrm{H}_{2} \mathrm{O}_{2}$ generation}

Surface engineering using insulated molecules and metalloporphyrin derivatives was next applied to the electrical devices. Cobalt chlorin complexes $\left[\mathbf{C o}^{\mathrm{II}}(\mathbf{C h})\right]$ have been reported as highly efficient and selective molecular catalysts for the two-electron selective reduction of dioxygen $\left(\mathrm{O}_{2}\right)$ to yield hydrogen peroxide $\left(\mathrm{H}_{2} \mathrm{O}_{2}\right)$ in homogeneous solution. ${ }^{67}$ However, the selectivity decreases when the catalysts are immobilized on the electrode surface. Owing to the disordered morphology of the surface-adsorbed $\mathbf{C o}^{\mathrm{II}}(\mathbf{C h})$, a $\mu$-1,2-peroxo dinuclear structure ${ }^{68}$ is formed, which carries on the four-electron-reduced dioxygen, producing $\mathrm{H}_{2} \mathrm{O}$ as a by-product. ${ }^{69}$ In this study, the high-degree independency and outstanding electrical properties of a [1] rotaxane-based hybrid system were applied to the $\mathbf{C o}{ }^{\mathrm{II}}(\mathbf{C h})$-catalyzed electrochemical device, to prevent the formation of $\mu$-1,2-peroxo dinuclear structures and enhance the charge-transfer efficiency. Insulated $\mathbf{5}$ and uninsulated $\mathbf{5}^{\prime}$ coordinated to $\mathbf{C o}^{\mathbf{I I}}(\mathbf{C h})$ were immobilized on FTO to form $\mathbf{C o}^{\text {III }}(\mathbf{C h})-5 /$ FTO $^{70}$ (Fig. 5a) and $\mathbf{C o}^{\text {II }}(\mathbf{C h})-5^{\prime} /$ FTO electrodes through the Langmuir-Blodgett (LB) technique at the same surface pressure, respectively. Both metal complexes formed a solid condensed monolayer on the FTO surface according to the pressure-area $(\pi-A)$ isotherms (Fig. S12). In addition, the Soret and Q bands of $\mathbf{C o}{ }^{\mathrm{II}}(\mathbf{C h})$ were observed in the differential absorption spectra of modified FTO in both Co"II(Ch)-5/FTO and Co"II(Ch)-5'/FTO (Fig. S13).

During the electrocatalytic synthesis, the $\mathbf{C o}^{\mathrm{II}}(\mathbf{C h})-\mathbf{5} /$ FTO system showed the best $\mathrm{H}_{2} \mathrm{O}_{2}$ production efficiency (Fig. 5d). In contrast, the Co ${ }^{\text {II }}$ (Ch)/FTO system, which directly deposited the catalyst on the FTO surface by the LB technique, exhibited the lowest production efficiency. The $\mathrm{H}_{2} \mathrm{O}_{2}$ production of the Co' ${ }^{\text {II }}(\mathbf{C h}) /$ FTO system declined after $1 \mathrm{~h}$ because of catalyst desorption, owing to the structure without 
phosphonic acid-based-anchoring portion. In addition, the catalyst films formed a $\mu$-1,2-peroxo dinuclear structure on the surface which, as previously mentioned, yielded $\mathrm{H}_{2} \mathrm{O}$ as a byproduct, thereby decreasing

317 the selectivity. Unlike the $\mathbf{C o}^{\text {II }}(\mathbf{C h}) /$ FTO system, the $\mathbf{C o} \mathbf{o}^{\text {II }}(\mathbf{C h})-5^{\prime} /$ FTO system contained an anchoring 318 portion to improve the adsorption stability. Although $\mathbf{C o}^{\text {II }}(\mathbf{C h})-\mathbf{5}^{\prime} /$ FTO exhibited a similar adsorption 319 density to that of its insulated counterpart in line with the absorption spectra (Fig. S14), the performance of 320 the $\mathbf{C o}{ }^{\text {II }}(\mathbf{C h})-5^{\prime} /$ FTO system was inferior. According to the previously described charge-transfer 321 experiment, the uninsulated structure of $\mathbf{5}^{\prime}$ was detrimental to charge transfer. This was suggested to be one 322 of the reasons for the lower production efficiency compared to that of the $\mathbf{C o}{ }^{\text {II }}(\mathbf{C h})-\mathbf{5} /$ FTO system. In 323 addition, because of the dependence on the uninsulated structure, the uninsulated $\mathbf{C o} \mathbf{o}^{\mathrm{II}}(\mathbf{C h})-\mathbf{5}^{\prime}$ complex formed a monolayer with intrinsically loose alignment on the FTO surface, while part of the $\mathbf{C o}^{\mathbf{I I}}(\mathbf{C h})$ portion formed a $\mu-1,2$-peroxo dinuclear structure, decreasing the selectivity. Consequently, improvement in the production efficiency of the $\mathbf{C o}^{\text {II }}(\mathbf{C h})-5 /$ FTO system should be considered independently of the insulated surface structure and charge transfer improvement.

\section{Discussion}

In summary, [1]rotaxane molecules bearing a phosphonic acid-derived PE as the conjugated backbone and PM $\alpha-\mathrm{CD}$ as a protective macrocycle were immobilized on metal oxide surfaces via a wet process. AFM and CV analyses revealed the insulation effects on the hybrid system of the [1]rotaxanes. The insulated molecules were immobilized on the metal oxide surfaces in ideal state without aggregation and displayed high charge-transfer efficiency at the interface, as compared to their uninsulated counterparts.

334 The high advantages of insulation were applied to electrocatalysis as electrical hybrid devices. The 335 [1]rotaxane system was utilized for the platform to introduce organic functionalities on the inorganic 336 electrode. The catalytic efficiency of the cobalt chlorin complex was markedly improved by utilizing 337 insulated molecules. These results indicate the importance of the [1]rotaxane strategy in isolating molecules 338 from unfavorable molecular interactions, even at the hybrid interface, providing excellent performance in 339 electrical hybrid devices. This methodology possesses high potential to upgrade the performances of 
existing electrical devices based on $\pi$-conjugated hybrid systems to outstanding devices, by improving the

341 independency and charge-transfer efficiency of the $\pi$-conjugated molecules at the hybrid interface. The

342 [1]rotaxane strategy can be considered as a general and versatile method for interfacial control, even for

343 other types of hybrid junctions in addition to phosphonic acid and tin oxides, which would efficiently solve

344 the conventional problems observed in hybrid interfaces composed of $\pi$-conjugated molecules and 345 inorganic materials.

Methods

Synthesis of 1

1,4-diiodobenzene (2.4 g, $7.27 \mathrm{mmol})$ was dissolved in degassed ${ }^{i} \operatorname{Pr}_{2} \mathrm{NH} / \mathrm{THF}(6 / 3 \mathrm{~mL})$. Under an argon, S1 $(1.00 \mathrm{~g}, 737 \mu \mathrm{mol}), \mathrm{PdCl}_{2}\left(\mathrm{PPh}_{3}\right)_{2}(51.8 \mathrm{mg}, 73.8 \mu \mathrm{mol})$ and $\mathrm{CuI}(7.0 \mathrm{mg}, 36.8 \mu \mathrm{mol})$ were added to the solution. The reaction mixture was stirred under an argon at room temperature overnight. The solvent was removed in vacuo, and the residue was purified by column chromatography on silica gel (1:1 toluene:EtOAc and 85:15 EtOAc:MeOH) to yield $\mathbf{S 2}$ as an orange solid (845 mg, $542 \mu \mathrm{mol}, 74 \%)$.

354 Under an argon atmosphere, $\mathrm{Pd}(\mathrm{OAc})_{2}(11.6 \mathrm{mg}, 51.6 \mu \mathrm{mol})$, dppf (57.3 mg, $\left.103 \mu \mathrm{mol}\right)$ and KOAc $(50.6$ $\mathrm{mg}, 516 \mu \mathrm{mol})$ were placed in the reaction vessel. THF $(20 \mathrm{~mL})$ was introduced and the mixture was stirred and heated at $68{ }^{\circ} \mathrm{C}$. After $5 \mathrm{~min}, \mathbf{S 2}(805 \mathrm{mg}, 517 \mu \mathrm{mol})$, diethyl phosphite $(666 \mu \mathrm{L}, 5.16 \mathrm{mmol})$ and

357 triethylamine (TEA) $(357 \mu \mathrm{L}, 2.58 \mu \mathrm{mol})$ were added to the mixture. The reaction mixture was stirred at $35868{ }^{\circ} \mathrm{C}$ overnight. The mixture was dried in vacuo, and the residue was purified by $\mathrm{GPC}$ with $\mathrm{CHCl}_{3}$ as the 359 eluent to yield 1 as an orange solid (609 mg, $388 \mu \mathrm{mol}, 72 \%)$. ESI MS: $(\mathrm{m} / \mathrm{z}) 1568.665\left([\mathrm{M}+\mathrm{H}]^{+}\right.$, $360 \mathrm{C}_{71} \mathrm{H}_{111} \mathrm{NO}_{35} \mathrm{P}$, calcd. 1568.667). ${ }^{1} H \mathrm{NMR}(500 \mathrm{MHz}, C D C l$, r.t.), $\delta: 7.82-7.80$ (m, 4H, ArH), 7.71-7.69 $361(\mathrm{~m}, 2 \mathrm{H}, \mathrm{ArH}), 7.61(\mathrm{~d}, J=8.5 \mathrm{~Hz}, 1 \mathrm{H}, \mathrm{ArH}), 5.09-2.99\left(\mathrm{~m}, 97 \mathrm{H}, \mathrm{CD}-\mathrm{H}, \mathrm{OCH}_{3}, \mathrm{OCH}_{2} \mathrm{CH}_{3}\right), 1.32(\mathrm{t}, J=$ $\left.3626.3 \mathrm{~Hz}, 6 \mathrm{H}, \mathrm{OCH}_{2} \mathrm{CH}_{3}\right) .{ }^{13} \mathrm{CNMR}\left(126 \mathrm{MHz}, \mathrm{CDCl}_{3}\right.$, r.t. $), \delta: 159.55,148.20,133.46,131.82(\mathrm{~d}, J=7.4 \mathrm{~Hz})$, $363131.72(\mathrm{~d}, J=12.6 \mathrm{~Hz}), 129.08(\mathrm{~d}, J=189.8 \mathrm{~Hz}), 126.50,126.47,119.4,116.0,106.7,100.44,100.29$, 
$100.21,100.18,100.13,100.03,97.3,86.8,82.73,82.60,82.54,82.52,82.47,82.21,82.19,82.15$ (peaks overlapped), 81.98, 81.94, 81.18, 81.14 (peaks overlapped), 81.12, 80.95, 71.71, 71.54 (peaks overlapped), 71.51, 71.44, 71.32, 71.29 (peaks overlapped), 71.28, 71.20, 70.19, 68.3, 62.33, 62.28, 61.88, 61.85 (peaks overlapped), 61.81, 61.79 (peaks overlapped), 59.33, 59.11 (peaks overlapped), 58.89, 58.25, 57.91, 57.86, 57.82, 57.81, 57.30, $16.33(\mathrm{~d}, J=6.5 \mathrm{~Hz}) .{ }^{31} \mathrm{P} N M R(202 \mathrm{MHz}, C D C l$, r.t. $), \delta: 17.59$.

\section{Synthesis of 2}

$1(30 \mathrm{mg}, 19 \mu \mathrm{mol})$ was added into $\mathrm{MeOH} / \mathrm{H}_{2} \mathrm{O}(1 / 1,30 \mathrm{~mL})$, and the solution was stirred at $60^{\circ} \mathrm{C}$ overnight.

371 The reaction mixture was evaporated to reduce $\mathrm{MeOH}$. The mixture was diluted with $\mathrm{CHCl}_{3}$ and washed 372 with water. The organic layer was separated and dried over $\mathrm{MgSO}_{4}$, and then filtered. The solvent was 373 removed by evaporation to yield 2 as a pale yellow solid (27 mg, $17 \mu \mathrm{mol}, 89 \%)$ without further purification. ESI MS: $(\mathrm{m} / z) 1590.648\left([\mathrm{M}+\mathrm{Na}]^{+}, \mathrm{C}_{71} \mathrm{H}_{110} \mathrm{NO}_{35} \mathrm{PNa}\right.$, calcd. 1590.649). ${ }^{1} \mathrm{H} N M R(500 \mathrm{MHz}, \mathrm{CDCl}$, r.t. $), \delta$ : 8.23-8.22 (m, 2H, ArH), 8.00-7.98 (m, 4H, ArH), $7.80(\mathrm{~d}, J=7.9 \mathrm{~Hz}, 1 \mathrm{H}, \mathrm{ArH}), 5.06-2.99(\mathrm{~m}, 97 \mathrm{H}$, $\left.\mathrm{CD}-\mathrm{H}, \mathrm{OCH}_{3}, \mathrm{OCH}_{2} \mathrm{CH}_{3}\right), 1.26\left(\mathrm{dd}, J=11.3,6.7 \mathrm{~Hz}, 6 \mathrm{H}, \mathrm{OCH}_{2} \mathrm{CH}_{3}\right) .{ }^{13} \mathrm{CNMR}\left(126 \mathrm{MHz}, \mathrm{CDCl}_{3}\right.$, r.t. $)$, $\delta$ : 162.06, 148.17, 134.05, $132.32(\mathrm{~d}, J=13.9 \mathrm{~Hz}), 131.41(\mathrm{~d}, J=10.1 \mathrm{~Hz}), 130.35(\mathrm{~d}, J=191.5 \mathrm{~Hz}), 125.19$, $123.28,117.90,116.81,100.72,100.54,100.11,99.98,99.90,97.96,97.19,87.39,83.56,83.26,82.90$, 82.54, 82.37, 82.34, 82.28 (peaks overlapped), 82.02 (peaks overlapped), 81.93, 81.91, 81.65, 81.34, 81.15, 81.09, 81.03, 80.98, 72.03 (peaks overlapped), 71.92, 71.57, 71.48, 71.44, 71.33 (peaks overlapped), 71.26, $71.12,70.62,70.48,61.96,61.93,61.84,61.79,61.71,61.66,61.58,61.56,58.99,58.88,58.81,58.57$, 58.51, 58.30, 58.01, 57.70, 57.62, 57.54, 57.46, 16.12 (d, $J=6.3 \mathrm{~Hz}) .{ }^{31} P \mathrm{NMR}\left(202 \mathrm{MHz}, \mathrm{CDCl}_{3}\right.$, r.t. $)$, $\delta$ : 16.46 .

\section{Synthesis of $\mathbf{3}^{\prime}$}

Under a nitrogen, $1(30.5 \mathrm{mg}, 19.4 \mu \mathrm{mol})$ was dissolved in TEA $/ \mathrm{CH}_{2} \mathrm{Cl}_{2}(0.16 / 2 \mathrm{~mL})$, and $\mathrm{TMSBr}(49 \mu \mathrm{L}$, $383 \mu \mathrm{mol})$ was added into the solution. After the reaction mixture was stirred at room temperature for $12 \mathrm{~h}$, 387 the solvent was removed by vacuum distillation and $5 \mathrm{~mL}$ of methanol was added to the resulting crude. 
After the dissolved crude was stirred at room temperature for another $12 \mathrm{~h}$, the solvent was evaporated in vacuo. The residue was dissolved in $\mathrm{CHCl}_{3}$ and washed by dilute aqueous $\mathrm{HCl}$ solution. The organic layer was separated and dried over $\mathrm{MgSO}_{4}$, then the solvent was removed in vacuo. Furthermore, the residue was dissolved in $\mathrm{MeOH}$ and washed by hexane. The $\mathrm{MeOH}$ layer was collected and concentrated to yield $\mathbf{3}^{\prime}$ as a pale yellow solid $(28.0 \mathrm{mg}, 18.5 \mu \mathrm{mol}, 95 \%)$. Surface immobilizations were carried out without further purifications. ESI MS: $(\mathrm{m} / \mathrm{z}) 1510.591\left([\mathrm{M}-\mathrm{H}]^{-}, \mathrm{C}_{67} \mathrm{H}_{101} \mathrm{NO}_{35} \mathrm{P}\right.$, calcd. 1510.590). ${ }^{1} \mathrm{H} N M R$ (500 MHz, $394 \mathrm{CDCl}_{3}$, r.t.), $\delta: 7.83-7.77(\mathrm{~m}, 4 \mathrm{H}, \mathrm{ArH}), 7.66-7.62$ (broad, 2H, $\left.\mathrm{ArH}\right), 7.56(\mathrm{~d}, J=8.1 \mathrm{~Hz}, 1 \mathrm{H}, \mathrm{ArH})$, $395 \quad 5.07-2.97\left(\mathrm{~m}, 93 \mathrm{H}, \mathrm{CD}-\mathrm{H}, \mathrm{OCH}_{3}\right) .{ }^{13} \mathrm{CNMR}\left(126 \mathrm{MHz}, \mathrm{CDCl}_{3}\right.$, r.t. $)$, $\delta: 159.54,148.10,133.21,131.50$ (d, $J=16.4 \mathrm{~Hz}), 131.00(\mathrm{~d}, J=10.1 \mathrm{~Hz}), 125.98,119.43,115.90,106.93,100.29$ (peaks overlapped), 100.17 (peaks overlapped), 100.09 (peaks overlapped), 99.98 (peaks overlapped), 97.48, 86.53, 82.63, 82.55, 82.46 (peaks overlapped), 82.38, 82.16 (peaks overlapped), 82.10 (peaks overlapped), 82.02, 81.96, 81.76, 81.25, 81.17 (peaks overlapped), 81.11, 71.69, 71.66, 71.49 (peaks overlapped), 71.28 (peaks overlapped), 71.23, 71.17, 70.34, 68.30, 67.94, 61.86, 61.79 (peaks overlapped), 61.74 (peaks overlapped), 61.72, 59.30, 59.09, 59.08, 59.06, 58.87, 58.16, 57.87, 57.81 (peaks overlapped), 57.77, 57.34. ${ }^{31} \mathrm{P} \mathrm{NMR}\left(202 \mathrm{MHz}, \mathrm{CDCl}_{3}\right.$, r.t.), $\delta: 18.74$.

\section{Synthesis of $\mathbf{3}$}

404 Under a nitrogen, $2(27.6 \mathrm{mg}, 17.6 \mu \mathrm{mol})$ was dissolved in TEA/ $\mathrm{CH}_{2} \mathrm{Cl}_{2}(0.15 / 2 \mathrm{~mL})$, and $\mathrm{TMSBr}(45 \mu \mathrm{L}$, $405383 \mu \mathrm{mol})$ was added into the solution, and the reaction mixture was stirred at room temperature for $12 \mathrm{~h}$. 406 After the solvent was removed by vacuum distillation, $5 \mathrm{~mL}$ of methanol was added to the resulting crude 407 and stirred at room temperature for another $12 \mathrm{~h}$. Then, the solvent was evaporated by vacuum. After the 408 residue was dissolved in $\mathrm{CHCl}_{3}$ and washed by dilute aqueous $\mathrm{HCl}$ solution, the organic layer was separated 409 and dried over $\mathrm{MgSO}_{4}$ and the solvent was removed in vacuo. Furthermore, the residue was dissolved in $410 \mathrm{MeOH}$ and washed by hexane. The $\mathrm{MeOH}$ layer was separated and concentrated to yield $\mathbf{3}$ as a pale yellow 411 solid (16.4 mg, $10.8 \mu \mathrm{mol}, 61 \%)$. Surface immobilizations were carried out without further purifications. 412 ESI MS: $(\mathrm{m} / z) 1510.593\left([\mathrm{M}-\mathrm{H}]^{-}, \mathrm{C}_{67} \mathrm{H}_{101} \mathrm{NO}_{35} \mathrm{P}\right.$, calcd. 1510.590). ${ }^{l} \mathrm{H} N M R\left(500 \mathrm{MHz}, \mathrm{CDCl}_{3}\right.$, r.t. $)$, , 8.22 
$413(\mathrm{~d}, J=5.0 \mathrm{~Hz}, 2 \mathrm{H}, \mathrm{ArH}), 8.08-8.03(\mathrm{~m}, 4 \mathrm{H}, \mathrm{ArH}), 7.81(\mathrm{~d}, J=8.2 \mathrm{~Hz}, 1 \mathrm{H}, \mathrm{ArH}), 5.09-3.01(\mathrm{~m}, 93 \mathrm{H}$,

$\left.414 \mathrm{CD}-\mathrm{H}, \mathrm{OCH}_{3}\right) .{ }^{13} \mathrm{CNMR}\left(126 \mathrm{MHz}, \mathrm{CDCl}_{3}\right.$, r.t. $), \delta: 162.11,148.16,133.92,132.14(\mathrm{~d}, \mathrm{~J}=13.9 \mathrm{~Hz}), 131.07$

$415 \quad(\mathrm{~d}, J=10.1 \mathrm{~Hz}), 123.61,118.06,116.98,100.64,100.23,100.08,100.06,99.92,97.93,83.54,83.08,82.56$,

$41682.45,82.32,82.12,82.07,81.96,81.77,81.55,81.34,81.17,81.15,81.08,80.93,80.72,80.55,80.46$,

$41772.24,72.15,71.68,71.54$ (peaks overlapped), 71.30, 71.28, 70.63, 61.82, 61.80, 61.64, 61.60, 61.55, 61.30,

$418 \quad 59.12,59.01,58.91,58.70,58.65,58.26,57.90,57.77,57.72$ (peaks overlapped), 57.68. ${ }^{31} P \mathrm{NMR}(202 \mathrm{MHz}$,

$419 \mathrm{CDCl}_{3}$, r.t.), $\delta: 16.86$.

420 Synthesis of $\mathbf{4}^{\prime}$

421 Under a nitrogen, $\mathbf{S 8}(29.8 \mathrm{mg}, 17.2 \mu \mathrm{mol})$ was dissolved in TEA $/ \mathrm{CH}_{2} \mathrm{Cl}_{2}(0.15 / 2 \mathrm{~mL})$, and $\mathrm{TMSBr}(44 \mu \mathrm{L}$,

$422346 \mu \mathrm{mol}$ ) was added into the solution. The reaction mixture was stirred at room temperature for $12 \mathrm{~h}$. After

423 this reaction completed, the solvent was removed by vacuum distillation and $5 \mathrm{~mL}$ of methanol was added

424 to the resulting crude. After the dissolved crude was stirred at room temperature for another $12 \mathrm{~h}$, the solvent

425 was evaporated by vacuum. The residue was dissolved in $\mathrm{CHCl}_{3}$ and washed by dilute aqueous $\mathrm{HCl}$ solution.

426 The organic layer was separated and dried over $\mathrm{MgSO}_{4}$, then the solvent was removed in vacuo.

427 Furthermore, the residue was dissolved in $\mathrm{MeOH}$ and washed by hexane. The $\mathrm{MeOH}$ layer was separated 428 and concentrated to yield $4^{\prime}$ as a red solid $(26.5 \mathrm{mg}, 15.8 \mu \mathrm{mol}, 92 \%)$. Surface immobilizations were carried 429 out without further purifications. $H R-E S I M S:(m / z) 1673.6056\left([\mathrm{M}-\mathrm{H}]^{-}, \mathrm{C}_{79} \mathrm{H}_{110} \mathrm{FeO}_{33} \mathrm{P}\right.$, calcd. 1673.6016). $430{ }^{1} H N M R(500 \mathrm{MHz}, C D C l$, r.t.), $\delta: 7.86(\mathrm{dd}, J=11.6,8.1 \mathrm{~Hz}, 2 \mathrm{H}, \mathrm{ArH}), 7.56(\mathrm{~d}, J=5.9 \mathrm{~Hz}, 2 \mathrm{H}, \mathrm{ArH})$, $4317.43(\mathrm{~d}, J=7.6 \mathrm{~Hz}, 1 \mathrm{H}, \mathrm{ArH}), 7.07-7.04(\mathrm{~m}, 2 \mathrm{H}, \mathrm{ArH}), 5.22-3.03\left(\mathrm{~m}, 102 \mathrm{H}, \mathrm{CD}-\mathrm{H}, \mathrm{OCH}_{3}, \mathrm{FcH}\right) .{ }^{13} \mathrm{C}$ $432 N M R\left(126 \mathrm{MHz}, \mathrm{CDCl}_{3}\right.$, r.t. $), \delta: 158.80,133.22,130.80(\mathrm{~d}, J=10.1 \mathrm{~Hz}), 130.71(\mathrm{~d}, J=13.9 \mathrm{~Hz}), 124.61$, $433124.09,123.93,114.58,112.78,100.62,100.25,100.18,100.16,100.13,99.73,95.40,90.06,86.54,85.92$, $43482.87,82.51$ (peaks overlapped), 82.46, 82.21, 82.16 (peaks overlapped), 81.91, 81.70, 81.26, 81.20 (peaks 435 overlapped), 81.15 (peaks overlapped), 80.96, 71.94, 71.78, 71.52 (peaks overlapped), 71.47 (peaks 436 overlapped), 71.33 (peaks overlapped), 71.29 (peaks overlapped), 71.21, 70.58, 69.94, 69.00, 67.63, 64.92, 
61.88 (peaks overlapped), 61.83 (peaks overlapped), 61.77, 61.71, 59.33, 59.20, 59.11 (peaks overlapped), 59.09, 58.35, 57.91, 57.81 (peaks overlapped), 57.78, 57.33. ${ }^{31} \mathrm{P} N M R\left(202 \mathrm{MHz}, \mathrm{CDCl}_{3}\right.$, r.t.), $\delta: 12.55$.

\section{Synthesis of 4}

Under a nitrogen, $\mathbf{S 6}(34.6 \mathrm{mg}, 20 \mu \mathrm{mol})$ was dissolved in TEA $/ \mathrm{CH}_{2} \mathrm{Cl}_{2}(0.17 / 2 \mathrm{~mL})$, and $\mathrm{TMSBr}(77 \mu \mathrm{L}$, $606 \mu \mathrm{mol})$ was added into the solution. The reaction mixture was stirred at room temperature for $12 \mathrm{~h}$. After this reaction completed, the solvent was removed by vacuum distillation and $5 \mathrm{~mL}$ of methanol was added to the resulting crude. After the dissolved crude was stirred at room temperature for another $12 \mathrm{~h}$, the solvent was evaporated by vacuum. The residue was dissolved in $\mathrm{CHCl}_{3}$ and washed by dilute aqueous $\mathrm{HCl}$ solution. The organic layer was separated and dried over $\mathrm{MgSO}_{4}$, then the solvent was removed in vacuo. Furthermore, the residue was dissolved in $\mathrm{MeOH}$ and washed by hexane. The $\mathrm{MeOH}$ layer was separated and concentrated to yield 4 as a red solid (28.5 mg, $17 \mu \mathrm{mol}, 85 \%)$. Surface immobilizations were carried out without further purifications. HR-ESI MS: $(\mathrm{m} / \mathrm{z}) 1673.6048\left([\mathrm{M}-\mathrm{H}]^{-}, \mathrm{C}_{79} \mathrm{H}_{110} \mathrm{FeO}_{33} \mathrm{P}\right.$, calcd. 1673.6016). ${ }^{l} H \mathrm{NMR}\left(500 \mathrm{MHz}, \mathrm{CDCl}_{3}\right.$, r.t.), $\delta: 8.15$ (broad, 2H, $\left.\mathrm{ArH}\right), 7.99$ (dd, $\left.J=13.2,8.1 \mathrm{~Hz}, 2 \mathrm{H}, \mathrm{ArH}\right), 7.43(\mathrm{~d}, J$ $=7.8 \mathrm{~Hz}, 1 \mathrm{H}, \mathrm{ArH}), 7.25(\mathrm{~d}, J=8.5 \mathrm{~Hz}, 2 \mathrm{H}, \mathrm{ArH}), 5.07-2.85\left(\mathrm{~m}, 102 \mathrm{H}, \mathrm{CD}-\mathrm{H}, \mathrm{OCH}_{3}, \mathrm{Fc}-\mathrm{H}\right) .{ }^{13} C N M R$ (126 MHz, $\mathrm{CDCl}_{3}$, r.t.), $\delta: 161.83,132.98,131.90$ (d, $\left.J=15.1 \mathrm{~Hz}\right), 131.05$ (d, $\left.J=10.1 \mathrm{~Hz}\right), 126.24,126.14$, $124.71,115.76,100.67,100.13,100.06,99.98,99.90,97.93,94.41,91.90,88.88,84.72,83.82,82.70,82.55$, $82.44,82.29,82.10,82.04,81.89,81.75,81.68,81.54,81.28,81.15,81.09,80.86,80.64,80.49,72.47$, 72.06, 71.80, 71.55 (peaks overlapped), 71.48, 71.45, 71.33, 71.17, 71.12, 70.60, 70.56, 70.21, 70.02, 69.28, $64.25,61.86,61.82,61.74,61.60,61.30,61.26,59.13,59.09,58.94,58.80,58.76,58.19,57.89,57.82$, 57.73 (peaks overlapped), 57.69. ${ }^{31} P \mathrm{NMR}\left(202 \mathrm{MHz}, \mathrm{CDCl}_{3}\right.$, r.t. $), \delta: 17.47$.

\section{Synthesis of $\mathbf{5}^{\prime}$}

Under a nitrogen, $\mathbf{S 1 3}(27.7 \mathrm{mg}, 17.0 \mu \mathrm{mol})$ was dissolved in TEA $/ \mathrm{CH}_{2} \mathrm{Cl}_{2}(0.23 / 2.5 \mathrm{~mL})$, and $\mathrm{TMSBr}(71$ $\mu \mathrm{L}, 554 \mu \mathrm{mol})$ was added into the solution. The reaction mixture was stirred at room temperature for $12 \mathrm{~h}$. After this reaction completed, the solvent was removed by vacuum distillation and $5 \mathrm{~mL}$ of methanol was 
added to the resulting crude. After the dissolved crude was stirred at room temperature for another $12 \mathrm{~h}$, the

462 solvent was evaporated by vacuum. The residue was dissolved in $\mathrm{CHCl}_{3}$ and washed by dilute aqueous $\mathrm{HCl}$

463 solution. The organic layer was separated and dried over $\mathrm{MgSO}_{4}$, then the solvent was removed in vacuo.

464 Furthermore, the residue was dissolved in $\mathrm{MeOH}$ and washed by hexane. The $\mathrm{MeOH}$ layer was separated 465 and concentrated to yield $\mathbf{5}^{\prime}$ as a yellow solid $(26.3 \mathrm{mg}, 16.8 \mu \mathrm{mol}, 99 \%)$. Surface immobilizations were 466 carried out without further purifications. HR-ESI MS: $(\mathrm{m} / \mathrm{z}) 1566.6326\left([\mathrm{M}-\mathrm{H}]^{-}, \mathrm{C}_{74} \mathrm{H}_{105} \mathrm{NO}_{33} \mathrm{P}\right.$, calcd. 467 1566.6306). ${ }^{1} H$ NMR (500 MHz, MeOD, r.t.), $\delta: 8.64$ (broad, 2H, PyH), 7.84-7.80 (m, 2H, ArH), 7.75-7.73 $468(\mathrm{~m}, 2 \mathrm{H}, \mathrm{ArH}), 7.67(\mathrm{~d}, J=4.0 \mathrm{~Hz}, 2 \mathrm{H}, \mathrm{PyH}), 7.52(\mathrm{~d}, J=7.8 \mathrm{~Hz}, 1 \mathrm{H}, \operatorname{ArH}), 7.27(\mathrm{~s}, 1 \mathrm{H}, \operatorname{ArH}), 7.23(\mathrm{~d}, J=$ $4697.9 \mathrm{~Hz}, 1 \mathrm{H}, \mathrm{ArH}), 5.13-2.97\left(\mathrm{~m}, 93 \mathrm{H}, \mathrm{CD}-\mathrm{H}, \mathrm{OCH}_{3}\right) .{ }^{13} \mathrm{C} \mathrm{NMR}(126 \mathrm{MHz}, \mathrm{MeOD}$, r.t. $)$, o: 172.96, 160.70, $470 \quad 148.63,135.59,134.26,132.53(\mathrm{~d}, J=13.9), 132.09(\mathrm{~d}, J=10.1 \mathrm{~Hz}), 127.83,126.62(\mathrm{~d}, J=191.5 \mathrm{~Hz})$, $471 \quad 124.09,116.81,115.61,101.38,100.93,100.89,100.45,100.33,100.28,100.22,97.21,96.17,88.45,83.73$, $47283.46,83.40,83.36,83.33,83.26,83.08$ (peaks overlapped), 83.02, 82.97, 82.87, 82.80 (peaks overlapped), $47382.69,73.35,73.32,73.23,73.20,72.98,72.91,72.60,72.54,72.45,72.37,71.74,69.26,62.31,62.28$, $47462.15,62.12,62.04,62.01,59.57,59.42,59.35$ (peaks overlapped), 59.32, 59.10, 58.66, 58.53, 58.44, 58.43, $475 \quad 58.08,49.00 .{ }^{31} P$ NMR (202 MHz, MeOD, r.t. $), \delta: 14.60$.

\section{Preparation of Modified ITO Substrates}

477 ITO substrates (surface roughness: average $0.7 \mathrm{~nm}$ (KURAMOTO)) or single crystalline ITO substrates 478 (atomically flat terraces and steps $(<0.2 \mathrm{~nm}))^{60,61}$ was used. Spectroscopic grade $\mathrm{MeOH}$ and $\mathrm{CHCl}_{3}$ were 479 used as solvents. Prior to use, the ITO surface was annealed with ozone at $200{ }^{\circ} \mathrm{C}$ for $15 \mathrm{~min}$. An annealed 480 ITO substrate was immersed in a methanol solution of the molecules for $12 \mathrm{~h}$ at room temperature, followed 481 by rinsing in $\mathrm{MeOH}$ as well as chloroform and drying through nitrogen flow.

\section{Electrochemical Measurement}

483 Cyclic voltammetry (CV) measurements were taken using a CHI 600B potentiostat with a one-compartment 484 cell under air. All measurements were carried out in $0.1 \mathrm{M}$ of tetrabutylammonium hexafluorophosphate 
$\left(\mathrm{TBAPF}_{6}\right)$ in $\mathrm{CH}_{2} \mathrm{Cl}_{2}$. The 4-modified ITO substrate and $4^{\prime}$-modified ITO substrate were used as the working electrode (electrode area: $3.5^{2} \pi \mathrm{mm}^{2}$ ), and a platinum wire was used as the counter electrode.

487 Potentials are referenced to an $\mathrm{Ag} / \mathrm{Ag}^{+}\left(10 \mathrm{mM} \mathrm{AgNO}_{3}\right.$ in $\left.0.1 \mathrm{M} \mathrm{TBAClO}_{4}-\mathrm{MeCN}\right)$ electrode.

488 Electrochemical hydrogen peroxide $\left(\mathrm{H}_{2} \mathrm{O}_{2}\right)$ production

489 Electrochemical $\mathrm{H}_{2} \mathrm{O}_{2}$ production was performed using a conventional three-electrode cell using $490 \mathbf{C o}^{\mathrm{II}}(\mathbf{C h})-\mathbf{5} / \mathrm{FTO}$ or $\mathbf{C o}^{\mathrm{II}}(\mathbf{C h})-\mathbf{5}^{\prime} / \mathrm{FTO}$, an $\mathrm{Au}$ coil counter electrode and a $\mathrm{Ag} / \mathrm{AgCl}$ reference electrode in 491 an oxygen $\left(\mathrm{O}_{2}\right)$-saturated aqueous solution $(8 \mathrm{~mL})$ in an aqueous perchloric acid $(\mathrm{pH} 1.3,0.1 \mathrm{M}, 11.0 \mathrm{~mL})$ 492 by applying constant voltage $(E=0.41 \mathrm{~V}$ vs. $\mathrm{Ag} / \mathrm{AgCl})$ to a working electrode. The cell was kept in dark 493 to prevent the unexpected decomposition of produced $\mathrm{H}_{2} \mathrm{O}_{2}$. The $\mathrm{O}_{2}$ bubbling was continued during the 494 photocatalytic reaction. The concentration of $\mathrm{H}_{2} \mathrm{O}_{2}$ produced in the reaction solution was determined by 495 spectroscopic titration with an acidic solution of oxo[5,10,15,20-tetra(4-pyridyl)porphyrinato]titanium(IV) complex (Ti(TPyP)). The stock solution of Ti(TPyP) was prepared by dissolving $3.40 \mathrm{mg}$ of $\mathrm{Ti}(\mathrm{TPyP})$ in

$497100 \mathrm{~mL}$ of $50 \mathrm{mM}$ hydrochloric acid. An aliquot of the reaction solution was sampled and diluted with a 498 certain amount of water depending on the concentration of $\mathrm{H}_{2} \mathrm{O}_{2}$. The diluted $\mathrm{H}_{2} \mathrm{O}_{2}$ solution was mixed to $4990.25 \mathrm{~mL}$ of $4.8 \mathrm{M}$ an aqueous solution of $\mathrm{HClO}_{4}(4.8 \mathrm{M}, 0.25 \mathrm{~mL})$ and the stock solution of Ti(TPyP) $(0.25$ $500 \mathrm{~mL}$ ). The mixed solution was then allowed to stand for $5 \mathrm{~min}$ at room temperature. The sample solution 501 was diluted to $2.5 \mathrm{~mL}$ with water and used for the UV-Vis absorption analysis to determine the absorbance 502 at $\lambda=450 \mathrm{~nm}$. A blank solution was prepared in a similar manner by adding distilled water instead of the 503 sample solution to Ti(TPyP) in the same volume with its absorbance designated as $A_{\mathrm{B}}$. The difference in 504 absorbance was determined as follows: $\Delta A_{450}=A_{\mathrm{S}}-A_{\mathrm{B}}$. The amount of $\mathrm{H}_{2} \mathrm{O}_{2}$ produced was determined 505 based on $\Delta A_{450}$ and the volume of the solution.

\section{Data Availability}

507 All other data that support the findings of this study are available within the article and its Supplementary 508 Information, or from the corresponding author upon reasonable request. 
509

510

511

512

513

514

515

\section{References}

1. Mir, S. H.; Nagahara, L. A.; Thundat, T.; Mokarian-Tabari, P.; Furukawa, H.; Khosla, A. Revieworganic-inorganic hybrid functional materials: an integrated platform for applied technologies. Journal of The Electrochemical Society 165, B3137-B3156 (2018).

2. Mallakpour, S.; Madani, M. A review of current coupling agents for modification of metal oxide nanoparticles. Prog. Org. Coatings 86, 194-207 (2015).

3. Minamiki, T.; Ichikawa, Y.; Kurita, R. The power of assemblies at interfaces: nanosensor platforms based on synthetic receptor membranes. Sensors 20, 2228-2255 (2020).

4. Zahran, Z. N.; Tsubonouchi, Y.; Mohamed, E. A.; Yagi, M. Recent advances in the development of molecular catalyst-based anodes for water oxidation toward artificial photosynthesis. ChemSusChem 12, 1775-1793 (2019).

5. Simão, C.; Mas-Torrent, M.; Crivillers, N.; Lloveras, V.; Artés, J. M.; Gorostiza, P.; Veciana, J.; Rovira, C. A robust molecular platform for non-volatile memory devices with optical and magnetic responses. Nat. Chem. 3, 359-364 (2011).

6. Wei, C.; Zhuang, J.; Zhang, D.; Guo, W.; Yang, D.; Xie, Z.; Tang, J.; Su, W.; Zeng, H.; Cui, Z. Pyridine-based electron-transport materials with high solubility, excellent film-forming ability, and wettability for inkjet-printed OLEDs. ACS Appl. Mater. Interfaces 9, 38716-38727 (2017).

7. Huang, Y.; Kramer, E. J.; Heeger, A. J.; Bazan, G. C. Bulk heterojunction solar cells: morphology and performance relationships. Chem. Rev. 114, 7006-7043 (2014).

8. Liu, D.; Miao, Q. Recent progress in interface engineering of organic thin film transistors with selfassembled monolayers. Mater. Chem. Front. 2, 11-21 (2018).

9. Pujari, S. P.; Scheres, L.; Marcelis, A. T. M.; Zuilhof, H. Covalent surface modification of oxide surfaces. Angew. Chem. Int. Ed. 53, 6322-6356 (2014). 
532

10. Miyachi, M.; Kobayashi, T.; Nishihara, H.; Yamanoi, Y.; Sendo, J.; Maeda, H.; Sakamoto, R.; Yabusaki, Y. A new method to generate arene-terminated $\mathrm{Si}(111)$ and $\mathrm{Ge}(111)$ surfaces via a palladium-catalyzed arylation reaction. J. Am. Chem. Soc. 134, 20433-20439 (2012).

11. Chouirfa, H.; Bouloussa, H.; Migonney, V.; Falentin-Daudré, C. Review of titanium surface modification techniques and coatings for antibacterial applications. Acta Biomater. 83, 37-54 (2019).

12. Meng, X. An overview of molecular layer deposition for organic and organic-inorganic hybrid materials: mechanisms, growth characteristics, and promising applications. J. Mater. Chem. A 5, $18326-18378$ (2017).

13. Zhang, L.; Cole, J. M. Dye aggregation in dye-sensitized solar cells. J. Mater. Chem. A 5, 1954119559 (2017).

14. Feng, S.; Li, Q. S.; Sun, P. P.; Niehaus, T. A.; Li, Z. S. Dynamic characteristics of aggregation effects of organic dyes in dye-sensitized solar cells. ACS Appl. Mater. Interfaces 7, 22504-22514 (2015).

15. Feng, S.; Li, Q. S.; Yang, L. N.; Sun, Z. Z.; Niehaus, T. A.; Li, Z. S. Insights into aggregation effects on optical property and electronic coupling of organic dyes in dye sensitized solar cells. J. Power Sources 273, 282-289 (2015).

16. Kong, G. D.; Byeon, S. E.; Park, S.; Song, H.; Kim, S. Y.; Yoon, H. J. Mixed molecular electronics: tunneling behaviors and applications of mixed self-assembled monolayers. Adv. Electron. Mater. 6, 1901157 (2020).

17. Magomedov, A.; Al-Ashouri, A.; Kasparavičius, E.; Strazdaite, S.; Niaura, G.; Jošt, M.; Malinauskas, T.; Albrecht, S.; Getautis, V. Self-assembled hole transporting monolayer for highly efficient perovskite solar cells. Adv. Energy Mater. 8, 1801892 (2018).

18. Bumm, L. A.; Arnold, J. J.; Cygan, M. T.; Dunbar, T. D.; Burgin, T. P.; Jones, L.; Allara, D. L.; Tour, J. M.; Weiss, P. S. Are single molecular wires conducting? Science 271, 1705-1707 (1996). 
19. Tian, L.; Wang, Y.; Zhang, Y.; Li, X.; Wu, W.; Liu, B. Molecular engineering of indoline dyes and their application in dye-sensitized solar cells: effect of planarity and side chain on interfacial chargetransfer processes. ACS Appl. Energy Mater. 4, 242-248 (2021).

20. Chen, H.; Lyu, G.; Yue, Y.; Wang, T.; Li, D. P.; Shi, H.; Xing, J.; Shao, J.; Zhang, R.; Liu, J. Improving the photovoltaic performance by employing alkyl chains perpendicular to the $\pi$-conjugated plane of an organic dye in dye-sensitized solar cells. J. Mater. Chem. C 7, 7249-7258 (2019).

21. Royakkers, J.; Bronstein, H. Macrocyclic encapsulated conjugated polymers. Macromolecules 54, 1083-1094 (2021).

22. Méhes, G.; Pan, C.; Bencheikh, F.; Zhao, L.; Sugiyasu, K.; Takeuchi, M.; Ribierre, J. C.; Adachi, C. Enhanced electroluminescence from a thiophene-based insulated molecular wire. ACS Macro Lett. 5, 781-785 (2016).

23. Wang, J. C.; Hill, S. P.; Dilbeck, T.; Ogunsolu, O. O.; Banerjee, T.; Hanson, K. Multimolecular assemblies on high surface area metal oxides and their role in interfacial energy and electron transfer. Chem. Soc. Rev. 47, 104-148 (2018).

24. Freitag, M.; Galoppini, E. Molecular host-guest complexes: shielding of guests on semiconductor surfaces. Energy Environ. Sci. 4, 2482-2494 (2011).

25. Domi, Y.; Ikeura, K.; Okamura, K.; Shimazu, K.; Porter, M. D. Strong inclusion of inorganic anions into $\beta$-cyclodextrin immobilized to gold electrode. Langmuir 27, 10580-10586 (2011).

26. Domi, Y.; Yoshinaga, Y.; Shimazu, K.; Porter, M. D. Characterization and optimization of mixed thiol-derivatized $\beta$-cyclodextrin/pentanethiol monolayers with high-density guest-accessible cavities. Langmuir 25, 8094-8100 (2009).

27. Xue, M.; Yang, Y.; Chi, X.; Yan, X.; Huang, F. Development of pseudorotaxanes and rotaxanes: from synthesis to stimuli-responsive motions to applications. Chem. Rev. 115, 7398-7501 (2015). 
28. Sévery, L., Szczerbiński, J., Taskin, M. et al. Immobilization of molecular catalysts on electrode surfaces using host-guest interactions. Nat. Chem. (2021). https://doi.org/10.1038/s41557-021-00652$\mathrm{y}$

29. Choi, H.; Kang, S. O.; Ko, J.; Gao, G.; Kang, H. S.; Kang, M.-S.; Nazeeruddin, M. K.; Grätzel, M. An efficient dye-sensitized solar cell with an organic sensitizer encapsulated in a cyclodextrin cavity. Angew. Chem., Int. Ed. 48, 5938-5941 (2009).

30. Ou, Y.; Chen, G.; Yin, J.; Yu, G. A.; Liu, S. H. Rotaxane based on terpyridyl bimetal ruthenium complexes and $\beta$-cyclodextrin as organic sensitizer for dye-sensitized solar cells. J. Coord. Chem. 64, 3062-3067 (2011).

31. Rotaxane structures, where the bulky stopper units prohibit the dissociation between the axles and cyclic molecules, have not been relatively utilized as hybrid components to improve the chargetransfer efficiency at the interface. On the other hand, rotaxane structures on hybrid surfaces have been reported in memory and switch applications because their cyclic components undergo shuttling along the axle upon external stimulation; see (a) Baroncini, M.; Casimiro, L.; de Vet, C.; Groppi, J.; Silvi, S.; Credi, A. Making and operating molecular machines: a multidisciplinary challenge. ChemistryOpen 7, 169-179 (2018). (b) Qu, D. H.; Wang, Q. C.; Zhang, Q. W.; Ma, X.; Tian, H. Photoresponsive hostguest functional systems. Chem. Rev. 115, 7543-7588 (2015). (c) Jia, C.; Li, H.; Jiang, J.; Wang, J.; Chen, H.; Cao, D.; Stoddart, J. F.; Guo, X. Interface-engineered bistable [2]rotaxane-graphene hybrids with logic capabilities. Adv. Mater. 25, $6752-6759$ (2013). (d) Green, J. E.; Wook Choi, J.; Boukai, A.; Bunimovich, Y.; Johnston-Halperin, E.; Deionno, E.; Luo, Y.; Sheriff, B. A.; Xu, K.; Shik Shin, Y.; Tseng, H.-R.; Stoddart, J. F.; Heath, J. R. A 160-kilobit molecular electronic memory patterned at 1011 bits per square centimetre. Nature 445, 414-417 (2007).

32. Leventis, A.; Royakkers, J.; Rapidis, A. G.; Goodeal, N.; Corpinot, M. K.; Frost, J. M.; Bučar, D. K.; Blunt, M. O.; Cacialli, F.; Bronstein, H. Highly luminescent encapsulated narrow bandgap polymers based on diketopyrrolopyrrole. J. Am. Chem. Soc., 140, 1622-1626 (2018). 
33. Pan, C.; Zhao, C.; Takeuchi, M.; Sugiyasu, K. Conjugated oligomers and polymers sheathed with designer side chains. Chem. - An Asian J. 10, 1820-1835 (2015).

34. Terao, J.; Tsuda, S.; Tanaka, Y.; Okoshi, K.; Fujihara, T.; Tsuji, Y.; Kambe, N. Synthesis of organicsoluble conjugated polyrotaxanes by polymerization of linked rotaxanes. J. Am. Chem. Soc. 131, 16004-16005 (2009).

35. Liu, J.; Numata, Y.; Qin, C.; Islam, A.; Yang, X.; Han, L. Circle chain embracing donor-acceptor organic dye: simultaneous improvement of photocurrent and photovoltage for dye-sensitized solar cells. Chem. Commun. 49, 7587-7589 (2013).

36. Terao, J.; Tanaka, Y.; Tsuda, S.; Kambe, N.; Taniguchi, M.; Kawai, T.; Saeki, A.; Seki, S. Insulated molecular wire with highly conductive $\pi$-conjugated polymer core. J. Am. Chem. Soc. 131, 1804618047 (2009).

37. Masai, H.; Yokoyama, T.; Miyagishi, H. V.; Liu, M.; Tachibana, Y.; Fujihara, T.; Tsuji, Y.; Terao, J. Insulated conjugated bimetallopolymer with sigmoidal response by dual self-controlling system as a biomimetic material. Nat. Commun. 11, 408 (2020).

38. Masai, H.; Terao, J. Stimuli-responsive functionalized insulated conjugated polymers. Polym. J. 49, 805-814 (2017).

39. Hosomi, T.; Masai, H.; Fujihara, T.; Tsuji, Y.; Terao, J. A typical metal-ion-responsive color-tunable emitting insulated $\pi$-conjugated polymer film. Angew. Chem. Int. Ed. 55, 13427-13431 (2016).

40. Masai, H.; Terao, J.; Makuta, S.; Tachibana, Y.; Fujihara, T.; Tsuji, Y. Enhancement of phosphorescence and unimolecular behavior in the solid state by perfect insulation of platinumacetylide polymers. J. Am. Chem. Soc. 136, 14714-14717 (2014).

41. Masai, H.; Terao, J.; Seki, S.; Nakashima, S.; Kiguchi, M.; Okoshi, K.; Fujihara, T.; Tsuji, Y. Synthesis of one-dimensional metal-containing insulated molecular wire with versatile properties directed toward molecular electronics materials. J. Am. Chem. Soc. 136, 1742-1745 (2014). 
627

628

629

630

631

632

633

634

635

636

637

638

639

640

641

642

643

644

645

646

647

648

649

42. Queffélec, C.; Petit, M.; Janvier, P.; Knight, D. A.; Bujoli, B. Surface modification using phosphonic acids and esters. Chem. Rev. 112, 3777-3807 (2012).

43. Kalek, M.; Jezowska, M.; Stawinski, J. Preparation of arylphosphonates by palladium(O)-catalyzed cross-coupling in the presence of acetate additives: synthetic and mechanistic studies. Adv. Synth. Catal. 351, 3207-3216 (2009).

44. Motion of threading/dethreading transformation is shown in Fig. S1 in the supporting information.

45. Chou, S.-Y.; Masai, H.; Tsuda, S.; Terao, J. Synthetic methodology for structurally defined and insulated molecular wires bearing non-centrosymmetric conjugated axle components via iterative intramolecular slippage. Chem. - An Asian J. 14, 1667-1671 (2019).

46. Masai, H.; Terao, J. Synthetic methodologies for structurally defined linked-[n]rotaxanes with permethylated cyclodextrins: platform for functionalized molecular electronics. Bull. Chem. Soc. Jpn. 92, 529-539 (2019).

47. Nishiyabu, R.; Kano, K. Double self-inclusion by rotating glucopyranose units in per- $O$-methylated $\beta$ cyclodextrin moieties attached to a porphyrin in aqueous solution. European J. Org. Chem. No. 24, 4985-4988 (2004).

48. Masai, H.; Terao, J.; Fujihara, T.; Tsuji, Y. Rational design for rotaxane synthesis through intramolecular slippage: control of activation energy by rigid axle length. Chem. - A Eur. J. 22, 66246630 (2016).

49. Ohta, H.; Orita, M.; Hirano, M.; Hosono, H. Surface morphology and crystal quality of low resistive indium tin oxide grown on yittria-stabilized zirconia. J. Appl. Phys. 91, 3547-3550 (2002).

50. Ohta, H.; Kambayashi, T.; Hirano, M.; Hoshi, H.; Ishikawa, K.; Takezoe, H.; Hosono, H. Application of transparent conductive substrate with atomically flat \& stepped surface for lateral growth of organic molecule: vanadyl-phthalocyanine. Adv. Mater. 15, 1258-1262 (2003). 
51. AFM underestimated the absolute height of $\mathbf{3}$ immobilized on the surface of a single-crystalline ITO because of the softness of $\mathbf{3}$ and the interaction between the AFM probe and sample surface according to the following references: (a) Jiao, Y.; Schäffer, T. E. Accurate height and volume measurements on soft samples with the atomic force microscope. Langmuir 20, 10038-10045 (2004). (b) Ebenstein, Y.; Nahum, E.; Banin, U. Tapping mode atomic force microscopy for nanoparticle sizing: tip-sample interaction effects. Nano Lett. 2, 945-950 (2002).

52. Steentjes, T.; Jonkheijm, P.; Huskens, J. Electron transfer processes in ferrocene-modified poly(ethylene glycol) monolayers on electrodes. Langmuir 33, 11878-11883 (2017).

53. Eckermann, A. L.; Feld, D. J.; Shaw, J. A.; Meade, T. J. Electrochemistry of redox-active selfassembled monolayers. Coord. Chem. Rev. 254, 1769-1802 (2010).

54. Elgrishi, N.; Rountree, K. J.; McCarthy, B. D.; Rountree, E. S.; Eisenhart, T. T.; Dempsey, J. L. A practical beginner's guide to cyclic voltammetry. J. Chem. Educ. 95, 197-206 (2018).

55. Bard, A. J.; Faulkner, R. L. Electrochemical Methods: Fundamentals and Applications, 2nd Ed. (John Wiley \& Sons, 2001).

56. Tian, H.; Dai, Y.; Shao, H.; Yu, H. Z. Modulated intermolecular interactions in ferrocenylalkanethiolate self-assembled monolayers on gold. J. Phys. Chem. C 117, 1006-1012 (2013).

57. Hanna, C. M.; Luu, A.; Yang, J. Y. Proton-coupled electron transfer at anthraquinone modified indium tin oxide electrodes. ACS Appl. Energy Mater. 2, 59-65 (2019).

58. Guo, Y.; Zhao, J.; Zhu, J. Study on the intermolecular interactions between the functional moieties in ferrocene-terminated alkanethiol self-assembled monolayer on gold. Thin Solid Films 516, 3051-3057 (2008).

59. Laviron, E. General expression of the linear potential sweep voltammogram in the case of diffusionless electrochemical systems. J. Electroanal. Chem. 101, 19-28 (1979). 
673

674

675

676

677

678

679

680

681

682

683

684

685

686

687

688

689

690

691

692

693

60. Wang, L.; Polyansky, D. E.; Concepcion, J. J. Self-assembled bilayers as an anchoring strategy: catalysts, chromophores, and chromophore-catalyst assemblies. J. Am. Chem. Soc. 141, 8020-8027 (2020).

61. Kiguchi, M.; Nakashima, S.; Tada, T.; Watanabe, S.; Tsuda, S.; Tsuji, Y.; Terao, J. Single-molecule conductance of $\pi$-conjugated rotaxane: new method for measuring stipulated electric conductance of $\pi$-conjugated molecular wire using STM break junction. Small 8, 726-730 (2012).

62. Zhang, B.; Sun, L. Artificial photosynthesis: opportunities and challenges of molecular catalysts. Chem. Soc. Rev. 48, 2216-2264 (2019).

63. Wang, J. C.; Violette, K.; Ogunsolu, O. O.; Hanson, K. Metal ion mediated electron transfer at dyesemiconductor interfaces. Phys. Chem. Chem. Phys. 19, 2679-2682 (2017).

64. Han, N.; Wang, Y.; Ma, L.; Wen, J.; Li, J.; Zheng, H.; Nie, K.; Wang, X.; Zhao, F.; Li, Y.; Fan, J.; Zhong, J.; Wu, T.; Miller, D. J.; Lu, J.; Lee, S.t-T.; Li, Y. Supported cobalt polyphthalocyanine for high-performance electrocatalytic $\mathrm{CO}_{2}$ reduction. Chem 3, 652-664 (2017).

65. Dalle, K. E.; Warnan, J.; Leung, J. J.; Reuillard, B.; Karmel, I. S.; Reisner, E. Electro- and solar-driven fuel synthesis with first row transition metal complexes. Chem. Rev. 119, 2752-2875 (2019).

66. Chemical structure of $\mathbf{S 1 2}$ :

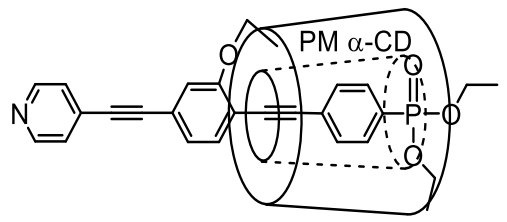

67. Mase, K.; Ohkubo, K.; Fukuzumi, S. Efficient two-electron reduction of dioxygen to hydrogen peroxide with one-electron reductants with a small overpotential catalyzed by a cobalt chlorin complex. J. Am. Chem. Soc. 135, 2800-2808 (2013).

68. Formation of $\mu$-1,2-peroxo dinuclear structure. 


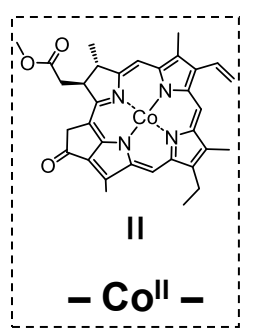

694

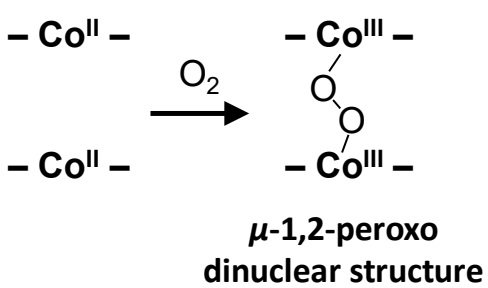

69. Mase, K.; Yoneda, M.; Yamada, Y.; Fukuzumi, S. Seawater usable for production and consumption of hydrogen peroxide as a solar fuel. Nat. Commun. 7, 11470 (2016). in Figure S11.

\section{Acknowledgements}

The authors would appreciate Shunichi Kaneko, Hiroki Hirano, and Yuichi Yasutake for their investigation

701 for the preliminary results. This research was supported by financial supports (JSPS KAKENHI Grant

702 Numbers 18H05158 in Scientific Research on Innovative Areas "Innovations for LightEnergy Conversion

703 (I4LEC)”, 19H02696, 19K22179, and 19K15629, JST CREST Grant Number JPMJCR1331). This work

704 was performed under the Cooperative Research Program of "Network Joint Research Center for Materials 705 and Devices".

707 Ethics declarations

708 Competing interests

709 The authors declare no competing interests.

\section{Supplementary Information}

711 Supplementary information is available for this paper at 


\section{Supplementary Files}

This is a list of supplementary files associated with this preprint. Click to download.

- SI.pdf 